\title{
Understanding the Co-Epidemic of Obesity and COVID-19: Current Evidence, Comparison with Previous Epidemics, Mechanisms, and Preventive and Therapeutic Perspectives
}

\author{
Maria Dalamaga $^{1} \cdot$ Gerasimos Socrates Christodoulatos $^{1} \cdot$ Irene Karampela ${ }^{1,2} \cdot$ Natalia Vallianou $^{3}$. \\ Caroline M. Apovian ${ }^{4}$
}

Accepted: 14 April 2021 / Published online: 28 April 2021

(C) The Author(s), under exclusive licence to Springer Science+Business Media, LLC, part of Springer Nature 2021

\begin{abstract}
Purpose of Review A growing body of evidence suggests that obesity and increased visceral adiposity are strongly and independently linked to adverse outcomes and death due to COVID-19. This review summarizes current epidemiologic data, highlights pathogenetic mechanisms on the association between excess body weight and COVID-19, compares data from previous pandemics, discusses why COVID-19 challenges the "obesity paradox," and presents implications in prevention and treatment as well as future perspectives.

Recent Findings Data from meta-analyses based on recent observational studies have indicated that obesity increases the risks of infection from SARS-CoV-2, severe infection and hospitalization, admission to the ICU and need of invasive mechanical ventilation (IMV), and the risk of mortality, particularly in severe obesity. The risks of IMV and mortality associated with obesity are accentuated in younger individuals (age $\leq 50$ years old). The meta-inflammation in obesity intersects with and exacerbates underlying pathogenetic mechanisms in COVID-19 through the following mechanisms and factors: (i) impaired innate and adaptive immune responses; (ii) chronic inflammation and oxidative stress; (iii) endothelial dysfunction, hypercoagulability, and aberrant activation of the complement; (iv) overactivation of the renin-angiotensin-aldosterone system; (v) overexpression of the angiotensin-converting enzyme 2 receptor in the adipose tissue; (vi) associated cardiometabolic comorbidities; (vii) vitamin D deficiency; (viii) gut dysbiosis; and (ix) mechanical and psychological issues.

Summary Mechanistic and large epidemiologic studies using big data sources with omics data exploring genetic determinants of risk and disease severity as well as large randomized controlled trials (RCTs) are necessary to shed light on the pathways connecting chronic subclinical inflammation/meta-inflammation with adverse COVID-19 outcomes and establish the ideal preventive and therapeutic approaches for patients with obesity.
\end{abstract}

Keywords Body mass index · COVID-19 · Cytokine storm · Diabetes · Infection · Inflammation · Influenza · Obesity · Pandemic $\cdot$ SARS-CoV-2 $\cdot$ Therapy

This article is part of the Topical Collection on Metabolism

Maria Dalamaga

madalamaga@med.uoa.gr

Gerasimos Socrates Christodoulatos

gerchristod82@hotmail.com

Irene Karampela

eikaras1@gmail.com

Natalia Vallianou

natalia.vallianou@hotmail.com

Caroline M. Apovian

Caroline.Apovian@bmc.org
1 Department of Biological Chemistry, Medical School, National and Kapodistrian University of Athens, Mikras Asias 75, Goudi, 11527 Athens, Greece

2 Second Department of Critical Care, Attikon General University Hospital, Medical School, National and Kapodistrian University of Athens, 1 Rimini St, Haidari, 12462 Athens, Greece

3 Department of Internal Medicine and Endocrinology, Evangelismos General Hospital of Athens, 45-47 Ypsilantou street, 10676 Athens, Greece

4 Section of Endocrinology, Diabetes, Nutrition, and Weight Management, Department of Medicine, Boston University School of Medicine and Boston Medical Center, Doctor's Office Building, 720 Harrison Avenue, Suite, Boston, MA 8100, USA 


\section{Introduction}

The novel coronavirus disease 2019 (COVID-19) caused by the severe acute respiratory syndrome coronavirus 2 (SARSCoV-2) represents an unprecedented public health challenge with a significant impact on morbidity and mortality as well as an unparalleled economic and health crisis worldwide. In March 2020, the World Health Organization (WHO) has officially declared COVID-19 a pandemic. Globally, as of December 30, 2020, there have been 80,773,033 confirmed cases of COVID-19, including 1,783,619 confirmed deaths reported to WHO in 222 countries, areas, or territories with cases, and these numbers continue to rise every day [1].

While SARS-CoV-2 is known to provoke substantial pulmonary disease, comprising pneumonia and acute respiratory distress syndrome (ARDS), COVID-19 may manifest with a wide range of extrapulmonary manifestations [2•]. The case fatality rate (CFR), i.e., the proportion of deaths from COVID19 compared to the total number of diagnosed patients, is around $2.21 \%$; while the estimated overall infection fatality rate (IFR), i.e., the proportion of deaths among all infected individuals including asymptomatic patients, ranges from 0.3 to $1 \%$ but is higher in older individuals with comorbidities $[1,3]$, including obesity. The COVID-19 pandemic has taken place at a time when the worldwide prevalence rate of overweight and obesity is greater than $39 \%$ for adults based on WHO data in 2016 [4]. The prevalence of obesity is particularly high in some countries such as the USA where the total number of confirmed COVID-19 cases and deaths is one of the highest in the world [1]. Data from the National Health and Nutrition Examination Survey have indicated that the ageadjusted prevalence of obesity among US adults was $42.4 \%$ in 2017 and 2018 [5]. It has been estimated that the global prevalence of overweight and obesity will exceed $57 \%$ by 2030 [6]. Individuals with obesity and COVID-19 are 113\% more likely to be admitted at hospitals, $74 \%$ more likely to be admitted to the intensive care unit (ICU), and 48\% more likely to die compared to subjects with normal weight [7]. All these data highlight the fact that COVID-19 and obesity pandemics converge into a co-epidemic or syndemic requiring an urgent and multidisciplinary approach [8].

Overweight and obesity are defined as excessive or abnormal fat accumulation that may impair health. Based on the WHO classification of obesity for adults of both genders and all ages, overweight is defined as a body mass index (BMI) greater than or equal to $25 \mathrm{~kg} / \mathrm{m}^{2}$, and obesity as a BMI greater than or equal to $30 \mathrm{~kg} / \mathrm{m}^{2}$. A more detailed classification of the severity of adulthood obesity includes 3 classes: class I (moderate) with BMI $30-34.9 \mathrm{~kg} / \mathrm{m}^{2}$; class II (severe) with BMI 35-39.9 kg/m² ; and class III (very severe) with BMI greater or equal to $40 \mathrm{~kg} / \mathrm{m}^{2}$ [9]. Although BMI is not considered the most reliable measure of body fat, it represents a practical and useful tool for assessing total body weight in a large population [10]. According to several studies, BMI is a strong independent risk factor for severe COVID-19, adjusting for age, gender, social class, diabetes mellitus, hypertension, and other comorbidities. In the largest descriptive epidemiologic study of hospitalized US COVID-19 patients, it was shown that $77 \%$ of approximately 17,000 patients had obesity (48\%) or overweight (29\%) [11]. Interestingly, higher BMI contributed more to the risk of severe COVID-19 and mortality in younger patients, i.e., those less than 50 years of age [12••, 13-16].

Obesity is associated with a wide range of adverse health outcomes. The unfavorable effects of excess body weight in the course of viral infections including COVID-19 have been mainly attributed to the metabolic perturbations and chronic inflammation of the adipose tissue leading to impaired immunity (blunted macrophage activation, impaired B and $\mathrm{T}$ lymphocyte responses) and more severe clinical outcomes [17, 18].

As of December 20, 2020, approximately 300 reviews on obesity and COVID-19 have been published in PubMed, shedding light on specific aspects of the association between obesity and COVID-19 without covering holistically epidemiologic, pathogenetic, and potential preventive and therapeutic aspects of the co-epidemic. The objective of this review is to provide current epidemiologic data regarding the association between excess body weight and COVID-19; to compare data with previous pandemics (H1N1 influenza 1918, SARS 2002, H1N1 influenza 2009, and Middle East respiratory syndrome [MERS] 2012), discussing also the reason of not observing a survival benefit (known as obesity paradox) of obesity in COVID-19-related acute respiratory distress syndrome (ARDS); to highlight potential pathophysiologic mechanisms explaining the association between obesity and COVID-19; to analyze racial/ethnic disparities in obesity and nutrition in COVID-19; and, finally, to present preventive and therapeutic implications and future perspectives.

\section{Literature Search}

PubMed, Scopus, Google Scholar, MedRxiv, and BioRxiv databases were accessed to identify English language articles published through December 20, 2020. The main search terms included "coronavirus," "cytokine," "human," "infection," "metabolism," "COVID-19," "immunity," "infection," "influenza," "obesity," "overweight," and "SARS-CoV-2." Additional publications of relevance were retrieved by reviewing the references of the eligible articles.

\section{Current Evidence of Epidemiologic Associations Between Obesity and COVID-19}

Table 1 depicts the list of main studies and meta-analyses associating obesity or BMI or visceral fat with COVID-19 risk 
and outcomes including the severity of infection, hospitalizations, hospitalizations in the ICU, administration of invasive mechanical ventilation (IMV), and mortality [19-23, 24••, 25-30, 31••, 32-47].

Based on three meta-analyses, the odds of SARS-CoV-2 positivity in individuals with obesity is $46-78 \%$ higher compared to individuals with normal weight [24••, 25, 26], while higher BMI was associated with a $28 \%$ elevated risk of COVID-19 per 1 standard deviation (SD) increase in $\mathrm{kg} / \mathrm{m}^{2}$ in a study using UK Biobank data ( $N=235,928$ participants) after multivariable adjustment including age, gender, ethnicity, and socioeconomic status [48]. BMI was less strongly associated with the risk of pneumonia or influenza [48]. Interestingly, the associations of forced expiratory volume in one second (FEV1), i.e., an index of lung function that may be improved with physical activity, and BMI with COVID-19 were linear, suggesting that even modest improvements in lifestyle could be beneficial to the risk of severe COVID-19 symptoms [48].

While elderly patients present an increased risk for severe COVID-19, younger patients with COVID-19 tend to have a higher BMI than older patients, with children suffering from obesity being at an elevated risk for severe disease $[12 \bullet \bullet, 15,16$, $49,50]$. In a case series of 50 children and adolescents hospitalized with COVID-19 in a children's hospital in New York City, the most prevalent comorbidity was overweight (16\%) and obesity (22\%). Obesity (BMI $\geq 95$ th percentile for age/ gender) was significantly associated with mechanical ventilation in children 2 years or older $(p=0.03)$ [50]. However, pediatric studies do not have a sufficient sample size to examine the independent association of BMI with severe COVID-19 outcomes. Based on data from 7606 patients hospitalized with COVID-19 at 88 US hospitals enrolled in the American Heart Association's (AHA) COVID-19 Cardiovascular Disease Registry, BMI $\geq 40 \mathrm{~kg} / \mathrm{m}^{2}$ was associated with a significantly greater odds of death or mechanical ventilation in those $\leq 50$ years old (OR: 1.64, 95\% CI: 1.23-2.21), and a moderately increased risk in those 51 to 70 years old (OR: $1.40,95 \%$ CI: 1.10-1.80), but no significant increase in risk for those $>70$ years old (OR: 1.28, 95\% CI: 0.83-1.95), adjusting for age, gender, race/ethnicity, history of cardiovascular disease (CVD), hypertension, diabetes, and chronic kidney disease (CKD) [12•*]. After adjustment for the abovementioned factors, the association of BMI with death or mechanical ventilation was strongest in adults $\leq 50$ years, intermediate in adults 51 to 70 years, and weakest in adults $>70$ years [12••]. Regardless of infection, age-related alterations in metabolic inflammation observed in obesity are still being under investigation, while this impact requires further analysis in COVID-19 [49]. In a Mendelian randomization study, genetic evidence supports BMI as a causal risk factor for COVID-19 susceptibility and severity $[27,51]$. Collectively, all these findings support the integration of BMI into the risk assessment of COVID-19.
Patients with obesity and type 2 diabetes mellitus (T2DM) could be at an increased propensity to experience a more severe infection associated with cytokine storm and a higher prevalence of thromboembolic complications associated with COVID-19 [12••]. Recent data have indicated that in patients presenting with metabolic associated fatty liver disease (MAFLD), obesity was associated with a 6-fold elevated risk for severe COVID-19 after adjusting for age, gender, smoking, diabetes, hypertension, and dyslipidemia [52, 53]. Besides, higher levels of serum inflammatory biomarkers such as $\mathrm{C}$-reactive protein (CRP), interleukin (IL)-6, ferritin, fibrinogen, D-dimer, erythrocyte sedimentation rate (ESR), and lactate dehydrogenase are predictive of subsequent critical illness and worse outcome in patients with COVID-19 [2•]. The majority of these inflammatory biomarkers are slightly elevated in individuals with obesity due to the chronic subclinical lowgrade inflammation that characterizes obesity [54-56]. Recent data have shown that patients with obesity and COVID-19 exhibited higher initial and peak levels of CRP and ESR as well as higher peak D-dimer in comparison to individuals with normal weight and COVID-19 after adjusting for age, gender, smoking, and comorbidities, suggesting greater disease severity characterized by more exuberant inflammation in individuals with obesity [55].

According to recent meta-analyses of retrospective and prospective cohort studies taking into account age, gender, ethnicity, and comorbidities, obesity almost doubled or quadrupled the risk of hospitalization due to COVID-19 [24••, 26, $31 \bullet \cdot, 32,46]$; increased the odds of being admitted to the ICU by $21-88 \%$ [24••, $26,32,37,38,46]$; and increased the odds of IMV by $66-113 \%$ [24••, 26, 32, 37, 46].

Very few data are published regarding adiposity measures reflecting central obesity, such as waist circumference (WC) and waist-to-hip ratio(WHR), and COVID-19 outcomes. Based on 9386 participants from the UK Biobank study tested for SARS-CoV-2, a higher WC was associated with an increased risk of testing positive for SARS-CoV-2 in participants $\geq 65$ years (relative risk [RR]: $1.12,95 \%$ CI: 1.00 1.27), adjusting for age, race, education, BMI, smoking status, alcohol use, and comorbidities [57]. In a prospective observational cohort study analyzing 166 patients with respiratory symptoms who presented at an emergency department in the Netherlands, increased WHR was an independent risk factor for respiratory distress in COVID-19 (OR 1.11, 95\% CI: 1.02-1.20), adjusting for age, gender, BMI, and metabolic syndrome. Based on recent meta-analyses of retrospective studies, an abnormal fat distribution, particularly visceral adipose tissue (VAT) expansion determined by computed tomography (CT)-based quantification, was found to be a significant independent factor of hospitalization, admission to the ICU, and worse clinical outcomes such as the need of intubation, adjusting for age, gender, and BMI [46, 47]. Difficult airway management and prone positioning (critical in the 


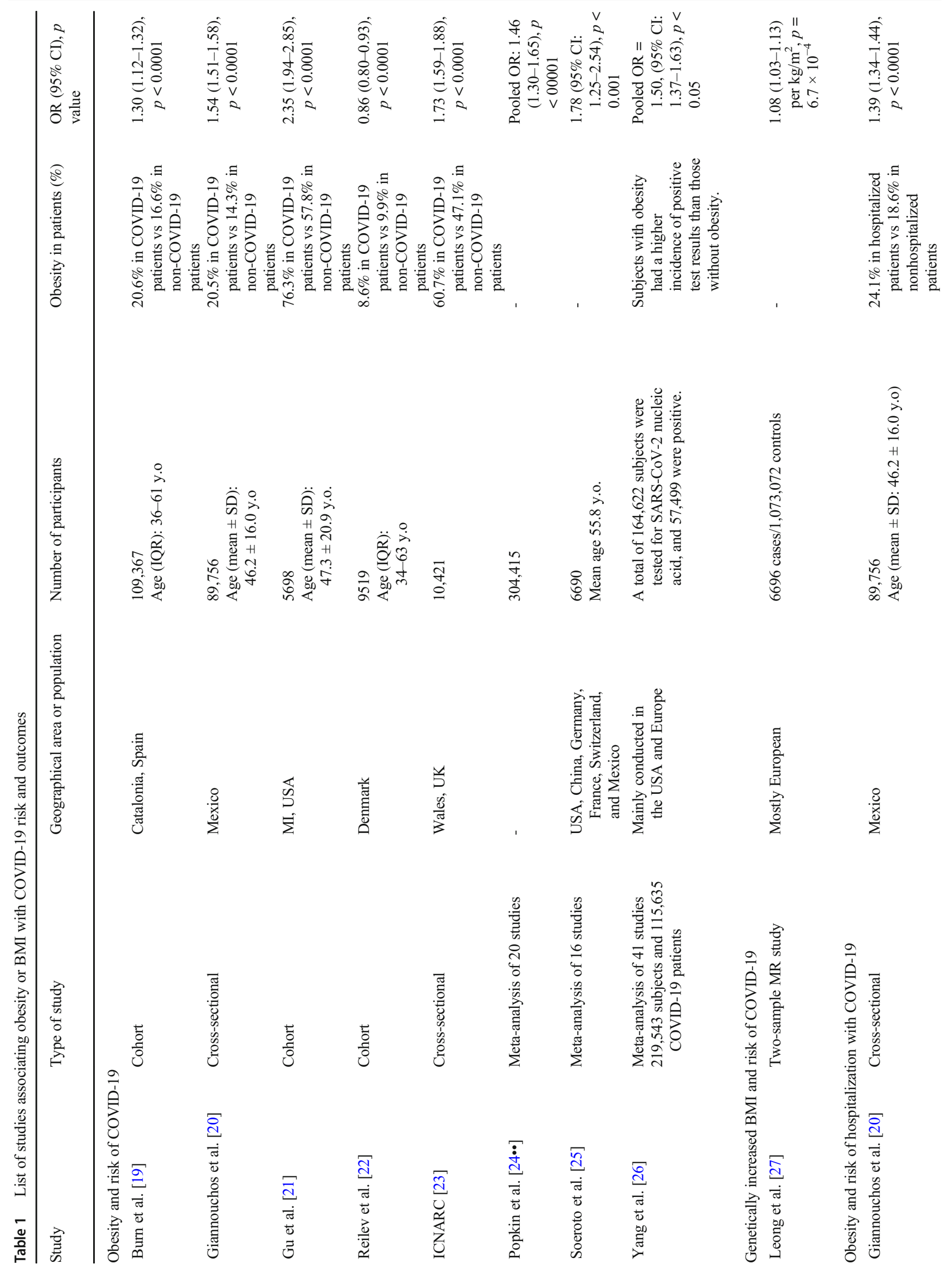




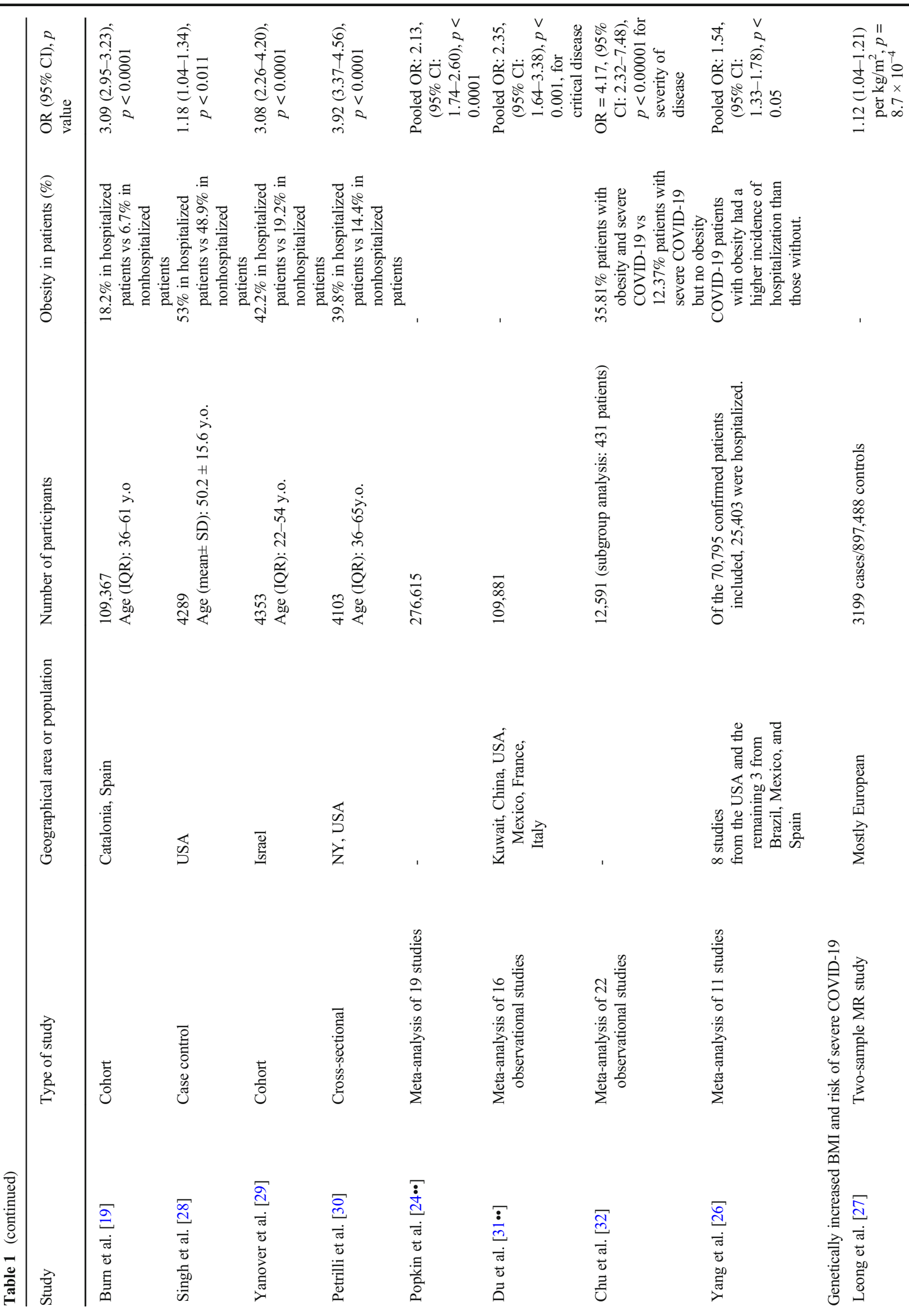




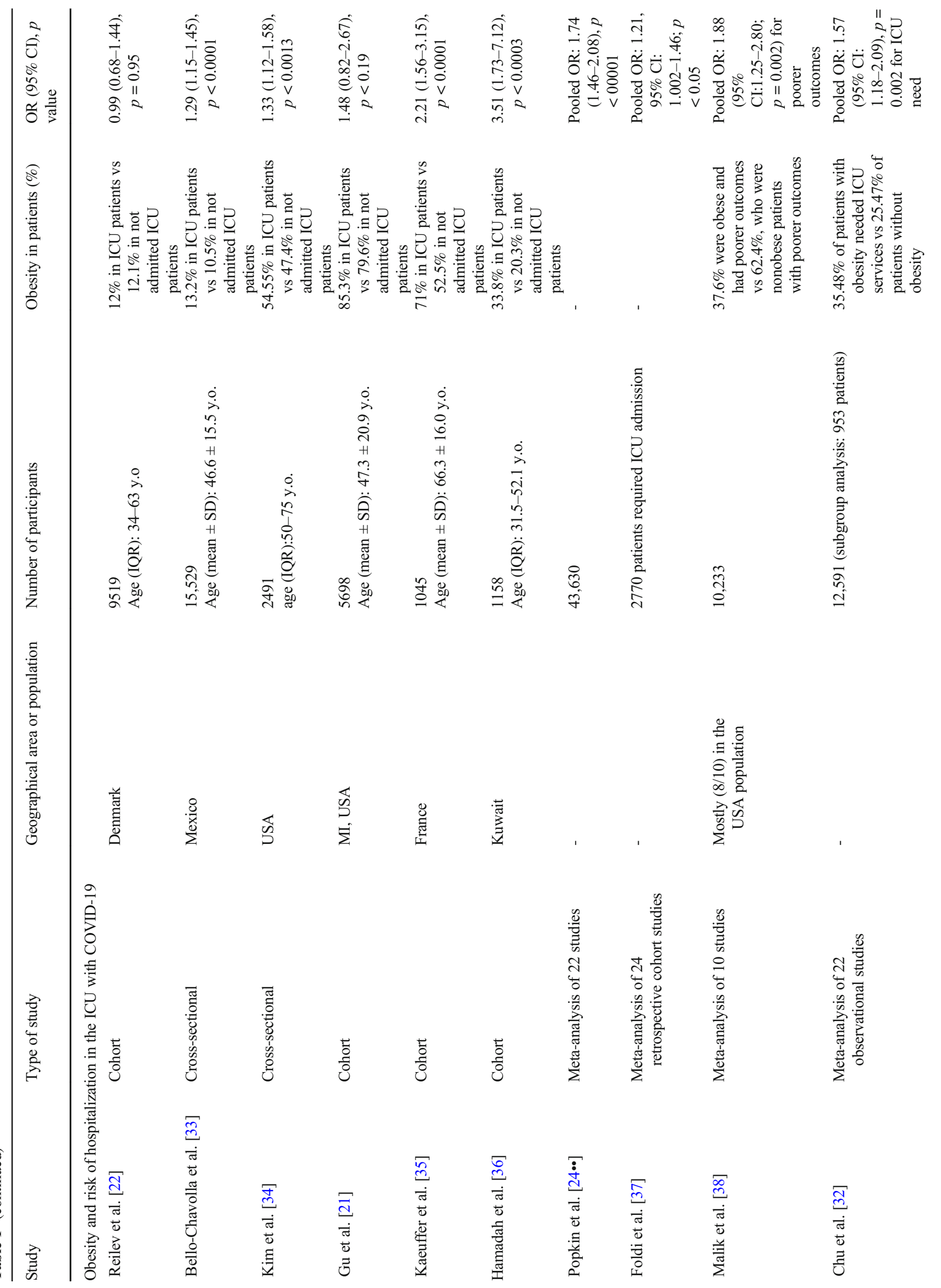




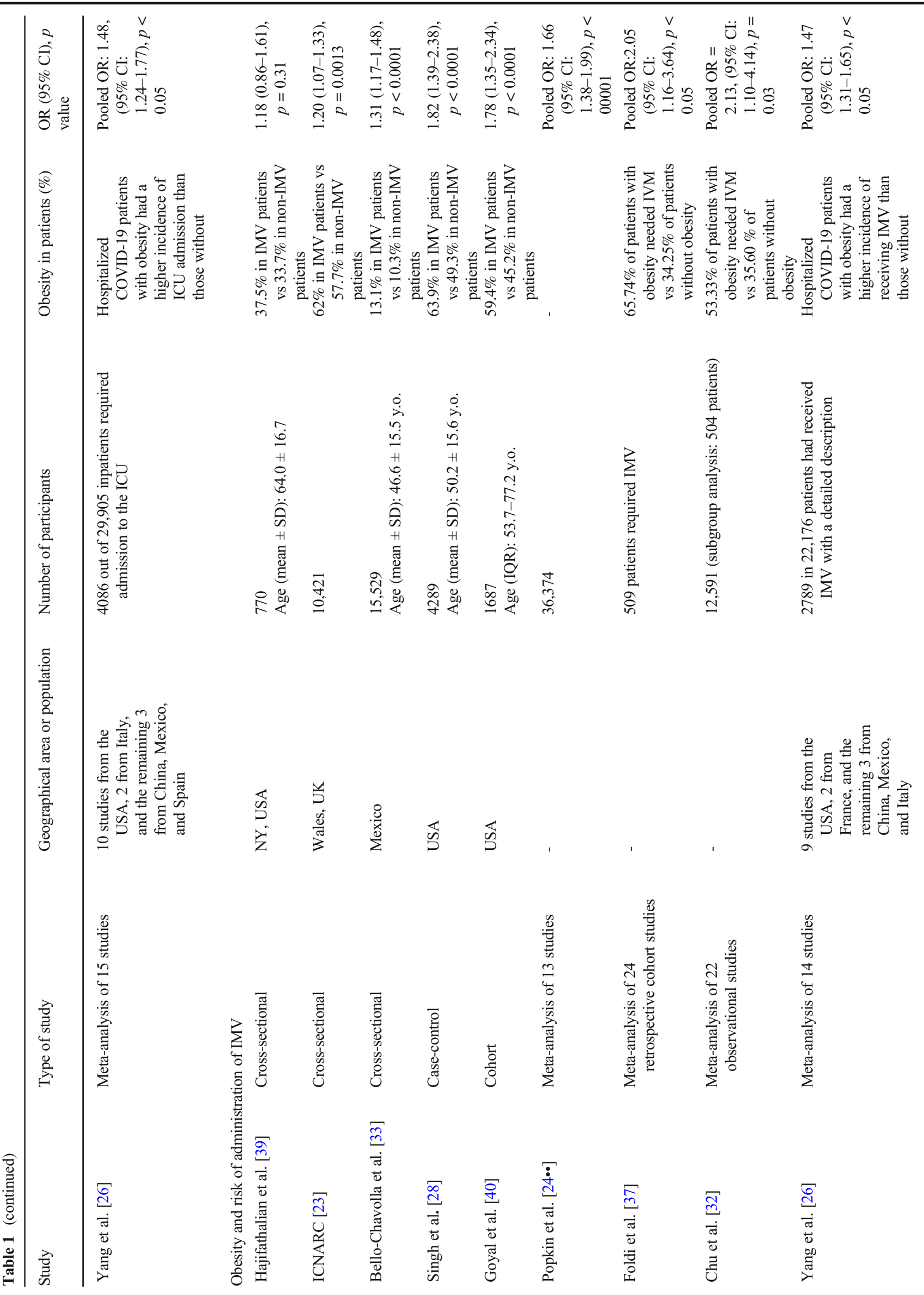




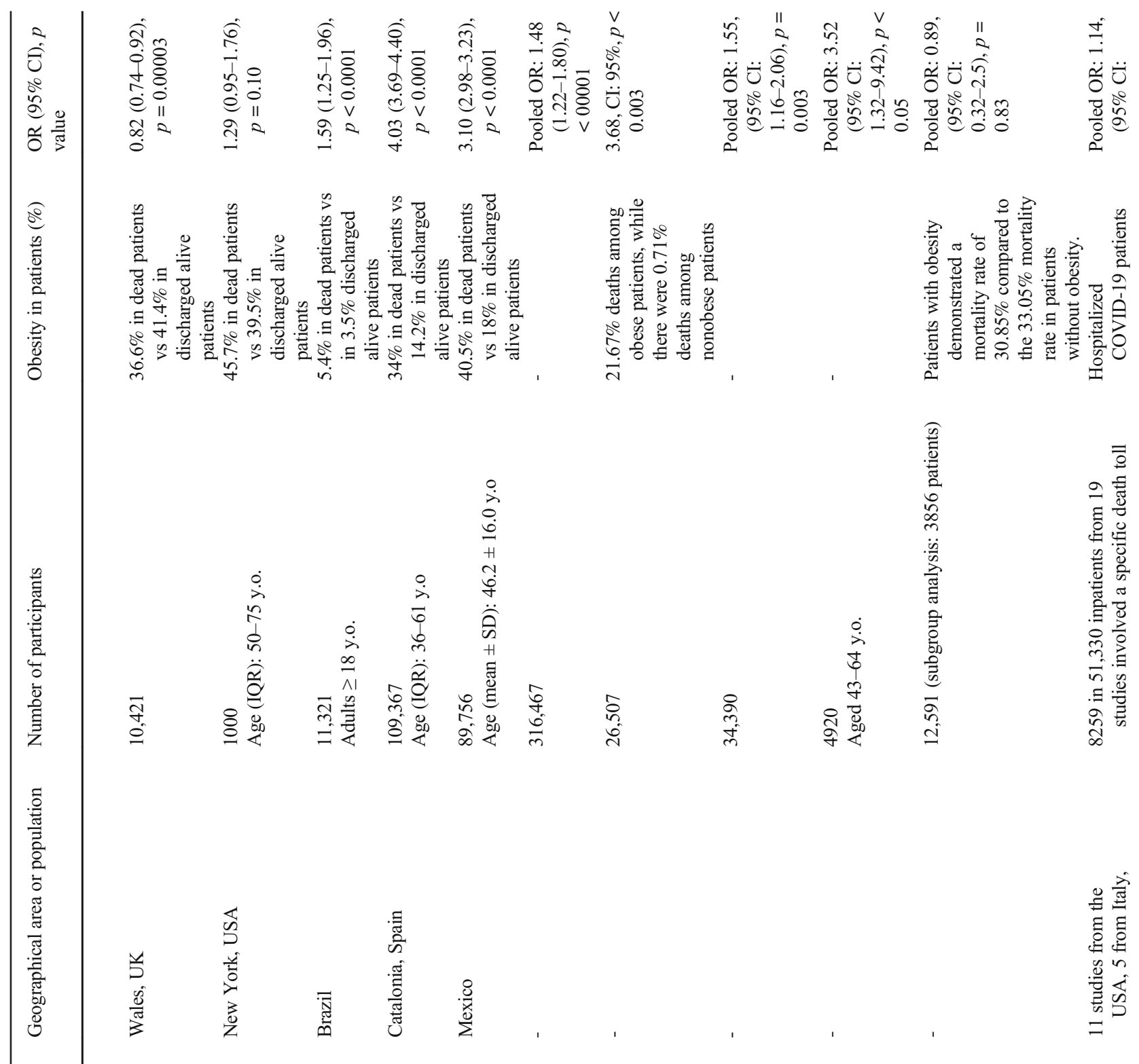




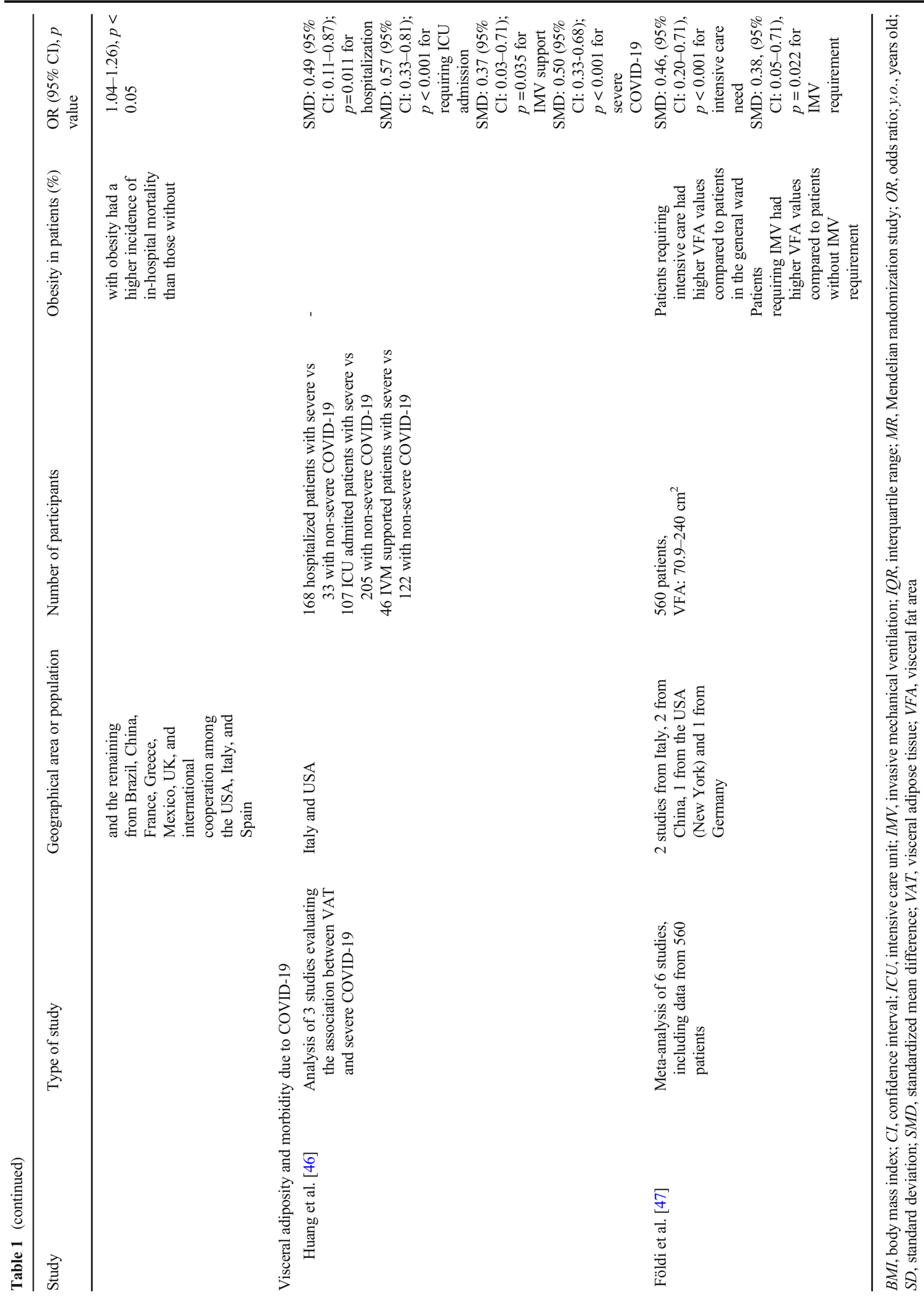


treatment of ARDS), which are routinely encountered with elevated BMI and WC, further aggravate the problem [58-60]. Patients with obesity are also at a higher risk for venous thromboembolism and dialysis [12••].

The majority of studies and meta-analyses have shown that obesity significantly elevated the hazard ratio of death amid COVID-19 patients with or without T2DM or T1DM [24••, $26,43-45,61]$. In a cohort study of 17 million British adult NHS patients using national primary care electronic health record data linked to in-hospital COVID-19 death data, the effect of obesity was very significant and graded according to the class of obesity with a hazard ratio for mortality being as high as 2.28 (95\% CI: 1.96-2.65) for individuals with very severe obesity $\left(\mathrm{BMI} \geq 40 \mathrm{~kg} / \mathrm{m}^{2}\right)$, adjusting for age, gender, ethnicity, and comorbidities [61]. Interestingly, in the large study of AHA COVID-19 Cardiovascular Disease Registry, very severe obesity was associated with an elevated risk of inhospital death only in those $\leq 50$ years (HR: $1.36,95 \% \mathrm{CI}$ : 1.01-1.84), adjusting for age, gender, race/ethnicity, history of CVD, hypertension, diabetes, and CKD [12••]. Among 25,952 SARS-CoV-2-positive patients in a large US cohort of Veterans Affairs enrollees, very severe obesity was associated with a higher risk of mortality (HR 1.42, 95\% CI: $1.12-$ 1.78) compared to normal-weight individuals, adjusting for age, gender, race/ethnicity, and comorbidities, with the strongest risk observed in those $<65$ years of age [13].

Not only are subjects with excess body weight at an increased risk for severe COVID-19 but also may spread SARS-CoV-2 and influenza virus more easily with prolonged virus shedding due to the higher viral load in the exhalation and the increased ventilation volume [62-64]. Individuals with obesity present a delay in synthesizing interferons which permit more viral RNA replication, increasing the chances of emergence of novel, more virulent viral strains [65].

Collectively from meta-analyses of retrospective and prospective studies, and a myriad of smaller studies, it appears clearly that obesity increases the risk of infection from COVID-19, the risks of severe infection, admission to the ICU, and IMV as well as the risk of mortality (particularly severe obesity), adjusting for age, gender, ethnicity, and comorbidities.

\section{Is the Association Between Obesity and Severe Infection Specific for COVID-19?}

Obesity as a risk factor for the severity of infections is not a new concept and is not restricted to COVID-19. Table 2 presents demographic and epidemiologic characteristics including risk factors of severe disease in main pandemics.

Since the Spanish flu, the influenza A/H1N1 pandemic in 1918 , it is known that malnutrition, observed in both undernutrition and overnutrition, is associated with an adverse outcome in viral infections [66]. Obesity represents an important risk factor for severe infection both for Orthomyxoviridae (influenza viruses) and Coronaviridae infections.

Obesity was a risk factor for a prolonged duration of infection, complications, and mortality in the 1957-1960 "Asian," the 1968 "Hong Kong," and the 2009 H1N1 influenza pandemics [67-72]. A study by the WHO regarding the 2009 H1N1 infection involving 70,000 individuals from 19 countries has shown that BMI $\geq 40 \mathrm{~kg} / \mathrm{m}^{2}$ is a risk factor for severe disease (unadjusted HR: 15.0, 95\% CI: 9.5-20.4) and mortality (unadjusted HR: 36.3, 95\% CI: 22.4-50.1) [73].

In a public health surveillance data of 534 California residents over 20 years of age and hospitalized with 2009 H1N1 infection, BMI $\geq 40 \mathrm{~kg} / \mathrm{m}^{2}$ (OR: $2.8,95 \% \mathrm{CI}: 1.4-5.9$ ) and BMI $\geq 45 \mathrm{~kg} / \mathrm{m}^{2}$ (OR: 4.2, 95\% CI: 1.9-9.4) were associated with death after adjusting for age, gender, race/ethnicity, miscellaneous immunosuppressive conditions, and asthma [71].

The same increased risk of disease severity, hospitalizations, adverse responsiveness to treatment, and mortality due to obesity has also been shown in seasonal influenza infections and other respiratory infections $[68,74,75]$. In a cohort of 4778 hospitalized and outpatient patients with seasonal influenza (778 with seasonal influenza; 2,636 with coronavirus, metapneumovirus, parainfluenza, and rhinovirus respiratory infections; and 1364 with influenza-like illness but no respiratory virus isolated) in Mexico, very severe obesity was associated with increased odds for hospitalization for both influenza (OR: 18.4, 95\% CI: 7.83-47.4) and other causes of respiratory infections (OR: 1.89, 95\% CI: 1.34-2.65), adjusting for age, gender, and presence of chronic conditions [68]. In a meta-analysis from six cross-sectional studies of 3059 subjects who were hospitalized for H1N1 infection, the pooled OR estimate for the risk of ICU admission or death was 2.01 (95\% CI: 1.293.14 ) for very severe obesity [75]. In parallel with viral infections, obesity may alter the progress of bacterial infections that complicate viral respiratory infections [76].

However, based on a study from the Centers for Disease Control and Prevention's Influenza Hospitalization Surveillance Network of almost 10,000 hospitalized cases of laboratoryconfirmed influenza in the USA, there was no evidence of obesity as a risk factor for requiring mechanical ventilation or mortality during the 2012-2013 influenza season [77].

Despite vaccination and the robust generated antibody titers against influenza vaccines by adults with obesity, obesity increases the risk of manifesting influenza and influenza-like disease [69]. In a prospective study of 1022 vaccinated subjects from NC, USA, vaccinated adults with obesity had double the risk for laboratory-confirmed influenza or influenzalike disease (RR: 2.01, 95\% CI: 1.12-3.60) compared to normal-weight participants, adjusting for vaccine year, age, gender, and smoking status [69].

Finally, in the previous SARS/2002 and Middle East respiratory syndrome (MERS)/2012 pandemics, which are caused 
Table 2 Demographic and clinical characteristics and obesity as a risk factor in main pandemics

\begin{tabular}{|c|c|c|c|c|c|}
\hline & $\begin{array}{l}\text { Pandemic H1N1 } \\
\text { influenza, } 1918\end{array}$ & $\begin{array}{l}\text { Pandemic H1N1 } \\
\text { influenza, } 2009\end{array}$ & $\begin{array}{l}\text { SARS pandemic, } \\
2002\end{array}$ & MERS pandemic, 2012 & $\begin{array}{l}\text { COVID-19 } \\
\text { pandemic, 2019- } \\
2020\end{array}$ \\
\hline First emergence & $\begin{array}{l}\text { Near-simultaneous } \\
\text { appearance in } \\
\text { March-April } 1918 \text { in } \\
\text { North America, } \\
\text { Europe, and Asia }\end{array}$ & $\begin{array}{l}\text { April 15, 2009, CA, } \\
\text { USA }\end{array}$ & $\begin{array}{l}\text { November 16, 2002, } \\
\text { Foshan, China }\end{array}$ & $\begin{array}{l}\text { April 4, 2012, Zarqa, } \\
\text { Jordan }\end{array}$ & $\begin{array}{l}\text { December 7, 2019, } \\
\text { Wuhan, China }\end{array}$ \\
\hline$\widehat{o}$ to $\rho$ ratio & Not known & $1.14: 1$ & $1.13: 1$ & $1.78-2.03: 1$ & $1.27: 1$ \\
\hline Incubation period, days & $2-7$ & $1-4$ & $2-7$ & $2-14$ & $4-12$ \\
\hline Transmission, Ro & 2 & 1.75 & 2.4 & 2.5 & 2.5 \\
\hline Herd immunity threshold & $\begin{array}{l}\text { 35\% (Geneva, spring } \\
\text { wave) } \\
75 \% \text { (Geneva, fall wave) }\end{array}$ & $25 \%$ (South Africa) & $72 \%$ & - & $60-80 \%$ \\
\hline $\begin{array}{l}\% \text { of patients with mild } \\
\text { disease }\end{array}$ & $\uparrow$ & $\uparrow$ & $\downarrow$ & $\downarrow$ & $\uparrow$ \\
\hline CFR & $2.5 \%$ or $\sim 4 \%$, or $\sim 10 \%$ & $\begin{array}{l}0.5 \% \\
\text { IFR: } \approx 0.1 \%\end{array}$ & $9.6 \%$ & $34.3 \%$ & $\begin{array}{l}\text { CFR: } 2.21 \% \\
\text { IFR: } 0.3-1 \%\end{array}$ \\
\hline Number of deaths & $17,000,000-100,000,000$ & $151,700-575,400$ & 774 & 858 & $1,783,619^{\ddagger}$ \\
\hline Mean age at death (years) & $27 \cdot 2$ & $37 \cdot 4$ & $\begin{array}{l}>65 \\
\text { Median age: } 75 \\
\quad \text { (Toronto SARS } \\
\quad \text { outbreak) }\end{array}$ & $>65$ & $>65$ \\
\hline $\begin{array}{l}\text { Risk factors for severe } \\
\text { disease }\end{array}$ & $\begin{array}{l}\text { Age }(\leq 5 \text { y.o., } 20-40 \text { y.o. } \\
\text { and } \geq 65 \text { y.o. })\end{array}$ & $\begin{array}{l}\text { Age ( } \leq 5 \text { y.o. and } \geq 65 \\
\text { y.o. }) \\
\text { Pregnancy } \\
\text { Comorbidities (CHD, } \\
\text { COPD, and DM) }\end{array}$ & $\begin{array}{l}\uparrow \text { Age } \\
\text { Male gender } \\
\text { Comorbidities (DM, } \\
\text { COPD, and CHD) }\end{array}$ & $\begin{array}{l}\uparrow \text { Age } \\
\text { Male gender } \\
\text { Comorbidities (HTN, } \\
\text { DM, COPD, and } \\
\text { CHD) }\end{array}$ & $\begin{array}{l}\uparrow \text { Age } \\
\text { Male gender } \\
\text { Comorbidities (HTN, } \\
\text { DM, COPD, and } \\
\text { CHD) }\end{array}$ \\
\hline Obesity as a risk factor & $\begin{array}{l}\text { Malnutrition } \\
\text { (undernutrition and } \\
\text { overnutrition) }\end{array}$ & $\begin{array}{l}\text { Subjects with obesity } \\
\quad\left(\mathrm{BMI} \geq 30 \mathrm{~kg} / \mathrm{m}^{2}\right) \\
\text { and very severe } \\
\text { obesity }(\mathrm{BMI} \geq 40 \\
\left.\mathrm{kg} / \mathrm{m}^{2}\right)\end{array}$ & $\begin{array}{l}\text { Not enough evidence } \\
\text { for the role of } \\
\text { obesity }\end{array}$ & $\begin{array}{l}\text { Not enough evidence } \\
\text { for obesity. Obesity } \\
\text { present in } 16 \pm 2 \% \\
\text { (95\% CI: } 12-19 \%) \\
\text { of cases }\end{array}$ & $\begin{array}{l}\text { Subjects with obesity } \\
\quad\left(\mathrm{BMI} \geq 30 \mathrm{~kg} / \mathrm{m}^{2}\right) \\
\text { and very severe } \\
\text { obesity }(\mathrm{BMI} \geq 40 \\
\left.\mathrm{kg} / \mathrm{m}^{2}\right)\end{array}$ \\
\hline
\end{tabular}

${ }^{\ddagger}$ As of December 30, 2020, based on https://covid19.who.int/

$B M I$, body mass index; $C F R$, case fatality ratio; $C H D$, coronary heart disease; $C O P D$, chronic obstructive pulmonary disease; $D M$, diabetes mellitus; $H T N$, hypertension; IFR, infection fatality rate; MERS, Middle East respiratory syndrome; SARS, severe acute respiratory syndrome; y.o., years old

by the coronaviruses SARS-CoV-1 and MERS-CoV respectively, obesity was listed among risk factors of MERS (but not SARS), along with male gender, older age, diabetes, hypertension, chronic heart disease, and chronic obstructive pulmonary disease (COPD) $[65,78 \cdot 79,80]$. In a meta-analysis of 637 MERS-CoV cases (representing approximately $40 \%$ of the WHO confirmed cases) in 12 retrospective studies with a small number of cases (range: 5-261) [80], obesity was present in $16 \pm 2 \%$ (95\% CI: $12-19 \%$ ) of cases. In the SARS pandemic with 8422 cases and 916 deaths, risk factors for severe disease and mortality included older age $(\geq 65$ years old) and presence of comorbidities, especially diabetes but not obesity [81]. As observed in a retrospective cohort study of 144 adult patients in the greater Toronto area (Toronto's SARS outbreak), with a diagnosis of suspected or probable SARS, diabetes was associated with poor outcomes, such as death, ICU admission, and mechanical ventilation (RR: 3.1, 95\% CI: 1.4-7.2), adjusting for age and comorbidities
(COPD, cancer, and CVD) [78•]. Due to the paucity of welldesigned studies with multivariable analyses, the lack of data on BMI in many studies, and the small number of patients with SARS and MERS in studies, the role of obesity has not been thoroughly explored $[65,78 \cdot, 79,80]$.

Overall, obesity is associated with both the risk and severity of respiratory infections; however, the association of obesity, particularly very severe obesity, with adverse outcomes including mortality is more prominent and consistent with 2009 H1N1 influenza and COVID-19 pandemics.

\section{Does SARS-CoV-2 Infection Challenge the "Obesity Paradox" Observed in ARDS?}

Based on findings from meta-analyses, overweight/obesity is related to a decrease in mortality risk in adult patients with ARDS and sepsis $[17,18,82,83 \cdot, 84,85]$. This survival benefit 
has been termed the "obesity paradox," and it has also been observed in various acute and chronic diseases, including heart failure, coronary artery disease, and chronic renal disease [17, 18]. However, the "obesity paradox" has been severely criticized on the grounds of flawed methodology. Indeed, a plethora of observational studies supporting the obesity paradox present significant limitations, such as their retrospective design, the heterogeneous study populations, the lack of adjustment for important confounding factors (severity of disease, preexisting illness and comorbidities, recent weight loss due to chronic disease, and the effects of treatment to outcome), the inherent limitations of measures of adiposity, and the presence of selection bias [17]. Moreover, in contrast to studies on adult populations, increased severity of sepsis and organ damage has been observed in pediatric patients with obesity compared to children of normal weight $[86,87]$. However, some studies on pediatric patients do not have a sufficient sample size to explore the independent association of obesity with adverse outcomes in ARDS and sepsis. Thus, the epidemiologic finding of the survival benefit of obesity in ARDS should be interpreted with caution.

As previously discussed in "Current Evidence of Epidemiologic Associations Between Obesity and COVID19 ," obesity represents an independent risk factor of infection, severe disease, and lethality. Main pathogenetic mechanisms linking obesity to the severity of COVID-19 include the impaired innate and adaptive immunity, chronic subclinical inflammation, endothelial dysfunction, and thrombotic tendency observed in obesity. Also, one potential mechanism involves the upregulation of the angiotensin-converting enzyme 2 (ACE2) receptor, the membrane-bound aminopeptidase interacting with the viral envelope spike glycoprotein of the SARS-CoV-2, in adipocytes of individuals with obesity and diabetes. Hence, the adipose tissue acts as a reservoir of the coronavirus allowing its replication and shedding, exacerbating the severity of disease and adverse outcomes through amplification of immune and cytokine activation $[88,89]$. Of note, an association between BMI and respiratory tract viral load has not been confirmed [90]. Other factors associating obesity with COVID-19 severity include (i) difficulties in placing patients with obesity in prone positioning, which is critical in managing ARDS, due to shortages of staff and equipment in the pandemic; (ii) the increased risk of impaired right ventricular contraction observed in patients with obesity, attributed to both increased sympathetic activation and circulating plasma volume; and (iii) the potential of difficulties in accessing care for patients with obesity during the pandemic [91].

\section{How Could the Meta-Inflammation in Obesity Intersect with and Exacerbate Underlying Pathogenetic Mechanisms in COVID-19?}

COVID-19 is characterized by a plethora of heterogeneous symptoms ranging from mild fatigue, anosmia, ageusia to life-threatening pneumonia, cytokine storm, and multiorgan failure $[2 \cdot]$.

SARS-CoV-2 enters human cells through the envelope spike glycoprotein, which is situated on the surface of the virus, being responsible for the host-to-host transmission, facilitating the entry of the virus into target cells. This glycoprotein binds to the ectoenzyme ACE2, a membrane-bound aminopeptidase, for cell entry. In addition, the cellular serine protease TMPRSS2 is needed for the prime entry of SARS-CoV-2 through ACE2. In the respiratory tract, ACE2 has the property to degrade angiotensin I into inactive angiotensin 1-9 and angiotensin II into angiotensin $1-7$, which exerts anti-inflammatory, vasodilator, and antifibrotic actions [2•]. When ACE1 enzymatic activity is increased and ACE2 is suppressed, angiotensin II exhibits proinflammatory actions via the angiotensin 1 receptor (AT1R) or AT2R, stimulating aldosterone production, increasing blood pressure, vascular permeability, and the risk of ARDS. ACE2 has emerged as a potent counter-regulator of the renin-angiotensin-aldosterone system (RAAS). Both SARS-CoV-2 and SARS-CoV-1 enter host cells via the ACE2 receptor, which is expressed in various tissues and organs, disrupting the beneficial biological activities of ACE2 (anti-inflammatory, anti-proliferative, anti-fibrotic, vasodilatory, and vascular protective) on counteracting the negative effects of the RAAS [92].

COVID-19 leads to increased cell apoptosis, triggering the stimulation of chemokines and pro-inflammatory cytokines, and the recruitment of inflammatory cells. SARS-CoV-2 provokes elevated apoptosis of lymphocytes, resulting in lymphocytopenia and impaired function associated with hypercytokinemia termed "cytokine storm" [92]. This mechanism resembles the macrophage activation syndrome (MAS), observed frequently in sepsis and severe viral infections, and characterized by the overproduction of circulating CXC-chemokine ligand 10 (CXCL10), monocyte chemoattractant protein-1 (MCP-1), macrophage inflammatory protein 1- $\alpha$ (MIP1- $\alpha$ ), interleukin (IL)-2, IL-6, IL-7, tumor necrosis factor- $\alpha$ (TNF- $\alpha$ ), and so on. MAS is linked to ARDS and multiorgan failure [93]. Key mechanisms that play a role in the pathogenesis of multi-organ involvement secondary to SARS-CoV-2 infection include (i) direct viral toxicity; (ii) impairment of the immune response; (iii) hyperinflammation; (iv) endothelial injury and thrombotic tendency; and (v) dysregulation of the RAAS [2•, 94-98]. Figure 1 depicts the links between obesity and the severity of COVID-19 clinical presentation, which is associated with metabolic and immune dysregulation. Based on currently available evidence, the following pathophysiologic mechanisms linking obesity to COVID-19 severity are discussed.

\section{Impaired Innate and Adaptive Immunity}

Individuals with obesity present both innate and adaptive immune dysfunction. Natural killer (NK) cells constitute effector 
lymphocytes of the innate immune system, which destruct virus-infected cells, such as SARS-CoV-2-infected cells, and tumor cells through the production of chemokines and interferon (IFN)- $\gamma$. There is mounting evidence suggesting that NK cell activity is reduced in obesity [99]. Diet-induced obese mice presented adverse clinical outcomes following respiratory viral infections such as influenza due to the reduction of NK cytotoxicity and mRNA expression of antiviral type I IFNs in the lungs [100].

Furthermore, macrophage activations against an antigen in conjunction with B- and T-cell responses, particularly CD8+ responses to viruses, are diminished in obesity [65]. Adaptive immunity is impaired in obesity with a plethora of studies indicating a decline in naive CD4+ cells and an imbalance of CD4+ T helper cells with a shift toward Th17 and Th22 responses $[101,102]$. Moreover, adipocytes in obesity infiltrate organs that produce and store immune cells, such as bone marrow, spleen, and thymus [7]. Likewise, patients with COVID-19 exhibit lower counts of CD4+ and CD8+ with an elevated ratio of proinflammatory Th17 cells [102]. Interestingly, expression of IFN $-\gamma$ by CD4+ cells is reduced in patients with severe COVID-19, and decreased circulating IFN- $\gamma$ is a risk factor of lung fibrosis in COVID-19 [103].

Therefore, inadequate antiviral response and host immune dysregulation may act synergistically, contributing to the development of severe COVID-19 in patients with obesity.

\section{Meta-Inflammation in Obesity and Immune Dysregulation}

Obesity represents a state of chronic low-grade subclinical inflammation tied with metabolic dysfunction, known as meta-inflammation. The dysfunctional hypertrophic adipose tissue in obesity synthesizes an excessive amount of adipokines including MCP-1, leptin, IL-6, IL-8, and plasminogen activator inhibitor-1 (PAI-1), which triggers the recruitment of inflammatory cells, especially polarized M1 macrophages [104-106]. In turn, the secretion of proinflammatory cytokines such as IL-6, IL-8, TNF- $\alpha$, MCP-1, and IL-1 $\beta$ by macrophages and the elevated circulating free fatty acids that upregulate the nuclear factor- $\mathrm{kB}(\mathrm{NF}-\mathrm{kB})$ pathway create a favorable milieu for the hyper-inflammatory response promoted through MAS in severe COVID-19 [107]. The proinflammatory state in obesity is further stimulated by the depletion of regulatory $\mathrm{T}$ cells (Tregs), which is linked to infiltration of immune cells and a rise in inflammation.

Like other coronaviruses infections, SARS-CoV-2 may generate a "cytokine storm" which can lead to ARDS or multiple organ failure. Cytokine storm is generally characterized by increased cytokine levels, acute systematic inflammatory symptoms, and secondary organ dysfunction attributed to an aberrant response to a pathogen if a pathogen is present [108]. COVID-19-associated cytokine storm is characterized by the release of increasing amounts of IL-6, IL- $1 \beta$, IL-12, IFN- $\gamma$, macrophage inflammatory protein (MIP) $1 \mathrm{a}$ and $1 \beta$, TNF- $\alpha$, and vascular endothelial growth factor (VEGF), with IL-6 being the most predictive cytokine of respiratory failure [49]. Besides elevated cytokine levels and activated CD4+ and CD8+ T cells, increased CRP and D-dimer levels as well as hypoalbuminemia are also observed. In contrast to other cytokine storm disorders, SARS-CoV-2-associated cytokine storm is characterized by lymphopenia, more frequent thromboembolic events, and less severely elevated cytokine levels, such as IL-6 [109••, 110].

The coexistence of obesity and associated disorders such as diabetes and hypertension with COVID-19 is linked to a more severe clinical course because of the preexisting chronic inflammation that characterizes obesity and/or a decreased threshold for the development of organ dysfunction due to the dysregulated immune response [108]. In particular, latestage, excessive inflammation contributes significantly to mortality $[111 \bullet \cdot$. Remarkably, as seen in SARS and MERS, IL-1 $\beta$ levels are upregulated in COVID-19 patients, attributed to the activation of the NOD-like receptor family pyrin domain containing 3 (NLRP3) inflammasome which is triggered by the SARS-CoV-2 viroporin [112]. Of note, NLRP3 expression is upregulated in obesity and plays a pivotal role in the activation and recruitment of macrophages [113]. Interestingly, the addition of the antirheumatic agents that block IL-1, IL-6, and inflammasome actions, such as anakinra, tocilizumab, and colchicine, in the standard of care in severe COVID-19 has shown promising results in nonrandomized clinical trials [114-117]. However, two large RCTs of anti-IL-6 receptor antibody treatment did not document a survival benefit in severe COVID-19 [118, 119]. Neutralization of a particular cytokine may not be effective if it is not the key component of the excessive pathologic inflammation circuit, which is considered an immunodeficiency state, predisposing patients, especially with obesity, to infections [108].

Adipose tissue, traditionally considered an energy storage organ, orchestrates immunometabolic functions by the production of adipokines such as leptin and adiponectin. Hyperleptinemia and leptin resistance, which are often observed in common obesity, are implicated in the expansion of Th1 cells and increased secretion of pro-inflammatory cytokines that sustain and enhance the development of immunoinflammatory responses [120,121]. Remarkably, hyperleptinemia and leptin resistance may aggravate clinical outcomes in respiratory infections, including COVID-19 [18, $122,123]$. Hypoadiponectinemia, frequently observed in obesity, may also facilitate a magnified inflammatory reaction directed to pulmonary capillaries [124]. In addition, resistin and lipocalin-2, two adipokines that are overexpressed in obesity and metabolic disorders $[125,126]$, were found amid the strongest predictors of critical illness in COVID-19 patients 


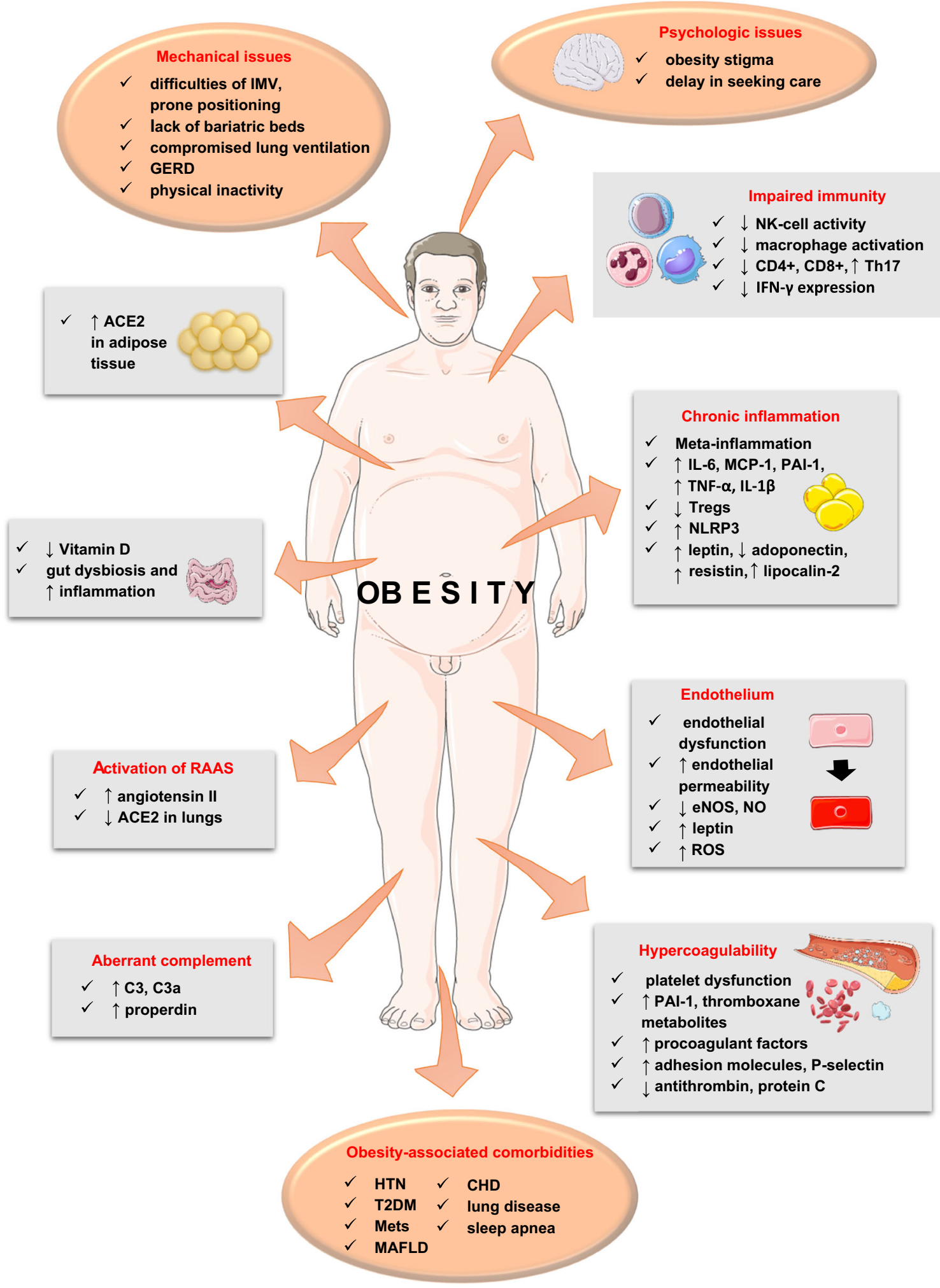

Fig. 1 Underlying pathophysiologic mechanisms and factors linking obesity to severe COVID-19. ACE2, angiotensin-converting enzyme 2; $\mathrm{CHD}$, coronary heart disease; eNOS, endothelial nitric oxide synthase; GERD, gastro-esophageal reflux disease; HTN, hypertension; IFN, interferon; IL, Interleukin; IMV, invasive mechanical ventilation; MAFLD, metabolic associated fatty liver disease; MCP-1, monocyte chemoattractant protein-1; Mets, metabolic syndrome; NK, natural killer; NLRP3, NOD-like receptor family pyrin domain containing 3; NO, nitric oxide; PAI-1, plasminogen activator inhibitor-1; RAAS, renin-angiotensin-aldosterone system; T2DM, type 2 diabetes mellitus; TNF- $\alpha$, tumor necrosis factor- $\alpha$; Tregs, regulatory T cell. (All images are derived from the free medical site http://smart.servier.com/ by Servier licensed under a Creative Commons Attribution 3.0 Unported License) 
$[127,128]$. It would be of interest to assess the clinical utility of circulating adipokines as biomarkers of clinical severity and prognosis in patients with COVID-19 and obesity.

\section{Endothelial Dysfunction and Oxidative Stress}

The role of the endothelium and endothelial injuries has been underscored in the pathogenesis of COVID-19 [129, 130]. Venous and arterial endothelium of several organs expresses ACE2 [131]. Histopathologic studies in patients with COVID-19 have revealed microscopic evidence of viral inclusion structures in endothelial cells, accumulation of inflammatory cells, such as activated neutrophiles and macrophages, in the endothelium, and endotheliitis found in multiple vascular beds of the heart, kidney, lungs, small intestine, and liver [2•]. Moreover, there is an over-responsive redox reaction to SARS-CoV-2. Reactive oxygen and nitrogen species may provoke unprecedented damage (redox storm) and activation of the innate and adaptive immune responses, with subsequent immune and cytokine storms. The clinical presentation of COVID-19 may be worse in susceptible patients with preexisting endothelial dysfunction. Dysfunction of the systemic microcirculation, including pulmonary vascular dysfunction, and increased endothelial permeability are well described in obesity and metabolic syndrome [132, 133]. The vasculoprotective and anti-inflammatory properties of nitric oxide (NO) are decreased in hyperinsulinemia and hyperleptinemia, which are common characteristics in obesity, due to (1) the reduction of the insulin-stimulated phosphoinositide 3-kinase (PI3K)-endothelial nitric oxide synthase (eNOS); (2) the chronic exposure of endothelial cells to hyperleptinemia; and (3) the increased oxidative stress attributed to RAAS, which results in the destruction of $\mathrm{NO}$ and the reduction of its bioavailability [107, 134, 135].

\section{Hypercoagulability, Thrombotic Tendency, and the Aberrant Activation of Complement}

Recent studies have reported that COVID-19 is associated with a high prevalence of arterial and venous thrombotic complications that include venous thromboembolism, myocardial infarction, and ischemic stroke [130]. Based on a US registry of hospitalized patients with COVID-19,35.3\% of critically ill and $2.6 \%$ of noncritically ill patients presented thrombotic events [136•]. The risk of thromboembolism is lower but undetermined in nonhospitalized patients [137]. SARS-CoV-2 infection-mediated endothelial injury, characterized by increased von Willebrand factor levels, and endotheliitis may lead to increased thrombin synthesis, suppression of fibrinolysis, activation of complement pathways, and initiation of thromboinflammation, resulting in microthrombi deposition in the lungs, heart, and kidneys [2•]. Histopathologic findings from autopsies of 38 patients with COVID-19 revealed the presence of microvascular thrombi, neutrophil extracellular traps, and neutrophil-platelet aggregates [138]. Interestingly, the immunohistological examination of the lungs and skin from patients with COVID-19 has shown the deposition of components of the alternative and lectin complement pathways [139].

In comparison to non-COVID-19 disorders, the thrombotic events in COVID-19 are related to SARS-CoV-2 endotheliitis, are more platelet dependent, and are associated with a hypercoagulability state characterized by increased levels of coagulation factors and acquired antiphospholipid antibodies as well as a decrease of endogenous anticoagulant proteins [140]. In particular, prothrombotic abnormalities include elevated levels of fibrinogen, D-dimer, and factor VIII. In COVID-19, thrombotic complications are more frequent in cases with severe systemic inflammation and respiratory distress [140].

Patients with obesity are more susceptible to the coagulopathy induced by the SARS-CoV-2 infection, adding to the severity and mortality risk of COVID-19 [7]. Obesity is characterized as a prothrombotic state exhibiting (i) platelet dysfunction and altered platelet indices; (ii) increased levels of PAI-1, which is oversecreted by the excess adipose tissue, impairing fibrinolysis; (iii) elevated thromboxane metabolites; (iv) upregulation of procoagulant factors and adhesion molecules, such as P-selectin, by the obesity-driven chronic inflammation; and (v) decreased anticoagulant regulatory proteins, such as antithrombin and protein C [141]. Interestingly, obesity is also characterized by modest elevations of the proteins of the complement pathways which could serve as a niche of pathologic inflammation and microthrombosis [142]. Adipocytes constitute a major source of several components of the complement system [143]. Increased adiposity and insulin resistance are associated with upregulated levels of C3, C3a, and properdin among others $[142,143]$.

\section{Overactivation of the RAAS}

As mentioned above, the maladaptive function of the RAAS, which participates in important physiologic processes of the organism such as blood pressure regulation, vascular permeability, and electrolyte and fluid balance, represents another potential pathogenetic mechanism of COVID-19-related tissue damage. The ACE2-angiotensin II balance is altered by both SARS-CoV-2 infection and obesity. Activation of RAAS in obesity with elevated levels of angiotensin II results in increased blood pressure, direct effects on the myocardium, and endothelial dysfunction [144]. Obesity, which is a wellestablished risk factor for CVD, is associated with left ventricular hypertrophy, diastolic dysfunction, and heart failure [145].

In the lungs, downregulation of ACE2 receptors, which are expressed predominantly by alveolar type 2 pneumonocytes 
(AT2) that express surfactant, causes immune-cell infiltration and expression of inflammatory cytokines resulting in lung edema and acute respiratory failure being mediated through angiotensin II [146]. In obesity, ectopic lipid deposition may appear in the cells of pulmonary alveoli, such as AT2, resulting in ultrastructural abnormalities, pulmonary inflammation, foam cell accumulation, altered surfactant production, and increased circulating surfactant proteins A and D [147-149]. "Fatty lung," the ectopic lipid deposition in AT2 cells, may influence the extent of alveolar damage caused by SARS-CoV-2 infection, participating in the causal pathway whereby obesity aggravates COVID-19 [61].

\section{Overexpression of ACE2 in Adipose Tissue}

Adipose tissue is considered a reservoir for influenza $\mathrm{A}$ and SARS-CoV-2 viruses [150]. SARS-CoV-2 shows tropism and high affinity for the ACE2 receptor, which is overexpressed in adipose tissue compared to lung tissue, and may favor prolonged viral shedding in subjects with obesity [88]. ACE2 upregulation in adipocytes from patients with obesity and T2DM permits viral entry and replication in the adipose tissue, potentially aggravating the severity of infection. However, BMI was not associated with increased initial respiratory tract viral load in a recent study [90].

\section{Obesity-Associated Comorbidities}

Individuals with obesity are more likely than individuals with normal weight to present other obesity-related comorbidities that are independent risk factors for severe COVID-19, including hypertension, T2DM, metabolic syndrome, MAFLD, coronary heart disease, lung disease, and sleep apnea [7, 12••, 151, 152]. Obesity, metabolic syndrome, and T2DM share common pathogenetic pathways, mainly the chronic, lowgrade inflammatory state, which could contribute to a more severe course of COVID-19. Indeed, meta-inflammation and impaired immune responses provide the ideal conditions for viral replication and enhanced pathogenesis. Delayed defense mechanisms trigger viral spread and replication, while excessive cytokine release favors persistent infections in these highrisk subjects [64]. Hyperglycemia, a key hallmark of T2DM which frequently accompanies obesity, may lead alone to significant alterations in macrophage function. In patients with diabetes, hyperglycemia and glycolysis may bolster SARS$\mathrm{CoV}-2$ replication in monocytes via the reactive oxygen species (ROS)/hypoxia-inducible factor 1-alpha (HIF-1 $\alpha$ ) pathway activation resulting in secondary $\mathrm{T}$-cell dysfunction [153]. Both insulin and leptin signaling are pivotal in the inflammatory response of T cells and the secretion of IFN- $\gamma$ and TNF- $\alpha$ through the upregulation of cellular glycolysis [154]. Importantly, patients with improved metabolic control were less likely to present severe COVID-19 and death [155].

\section{Vitamin D Deficiency in Obesity}

Based on a recent meta-analysis of 8176 COVID-19 patients participating in 26 studies, individuals with severe COVID-19 presented 65\% (OR: 1.65, 95\% CI: 1.30-2.09) more vitamin D deficiency $(<50 \mathrm{nmol} / \mathrm{L})$ compared with mild cases of the infection. Interestingly, a serum vitamin D concentration of less than $75 \mathrm{nmol} / \mathrm{L}$ increased hospitalization by $81 \%$ (OR: 1.81, 95\% CI: 1.41-2.21) and mortality by $82 \%$ (OR: $1.82,95 \%$ CI: $1.06-2.58)$ from COVID-19 [156]. However, vitamin D deficiency (OR: 1.35 , 95\% CI: 0.80-1.88) was not associated with an increased likelihood of COVID-19 infection [156, 157].

At the molecular level, vitamin D and its receptor (VDR), which is expressed on immune (B cells, T cells, and antigenpresenting cells) and pulmonary epithelial cells, plays an important role in both the innate and adaptive immune responses [158]. Vitamin D induces the transcriptional expression of antimicrobial peptides such as cathelicidins and defensins. Cathelicidins act by destructing the bacterial cell membranes and the enveloped viruses such as SARS-CoV-2, while defensins enhance chemotaxis of inflammatory cells through increased capillary permeability [158]. At the same time, vitamin D decreases pro-inflammatory cytokines, such as IL-6 and TNF- $\alpha$, which are involved in the development of the cytokine storm in COVID-19 that precedes ARDS [159].

Remarkably, obesity is associated with vitamin D deficiency due to the lipophilic nature of the adipose tissue which acts as an isolator of vitamin D rather than a depot [160]. Other mechanisms linking higher BMI to lower vitamin D include the lesser skin exposure to sunlight, the diminished outdoor physical activity, the lower vitamin D intake, and the reduced intestinal absorption of vitamin D [161, 162].

Interestingly, vitamin D deficiency has been found to be an independent risk factor for the development of ARDS, its severity, and mortality. Notably, a bulk of recent studies have reported that vitamin D deficiency is associated with severe COVID-19 and a higher risk for progression to ARDS [163]. Interestingly, the biologic pathways involved in the pleiotropic actions of vitamin D intersect with the dysregulated mechanisms during COVID-19-related ARDS, providing some possible explanations behind this association. Vitamin D and its metabolites are implicated in the ACE2 expression, modulate genes associated with thrombotic pathways, particularly those related to angiogenesis, activate the lung-protective cathelicidin, and downregulate pro-inflammatory cytokines blocking the cytokine storm, such as TNF- $\alpha$, IL-6, IL-8, IL12 , and IFN- $\gamma$ [163]. Collectively, vitamin D deficiency may be a potential link between obesity and COVID-19-associated ARDS [164]. However, the exact efficacy of vitamin D supplementation for the prevention of or as a potential adjunct therapeutic option for COVID-19 remains to be determined. Currently, a number of RCTs are actively investigating the potential benefits of vitamin D supplementation. 


\section{Gut Dysbiosis in Obesity}

The gut microbiome may modulate the host immune response, protect from infection, and dissipate the subsequent damage from infection [165]. Gut dysbiosis is another significant factor which may be implicated in the higher risk of severe COVID-19 in obesity. Obesity per se is characterized by a reduction in gut microbiota diversity and richness, a significantly higher abundance of Firmicutes, and a lower abundance of Bacteroidetes as well as an aberrant composition of the gut microbiome. However, there is still much debate on the exact microbial signature of a healthy or an obese gut microbiome [166-168]. Due to gut dysbiosis in obesity, the gut lipopolysaccharide (LPS), known as endotoxin, may be deviated from the immunosilent Bacteroidetes LPS subtypes to the diverse proinflammatory LPS subtypes, particularly from phyla secreting more inflammatory LPS, with a capacity to activate the toll-like receptor (TLR)-4-NF- $\mathrm{kB}$ pathway and elicit the secretion of inflammatory cytokines [168]. In a preprint study, it was shown that an interaction between SARS-CoV-2 spike protein and LPS, forming a high molecular weight aggregate, leads to aggravated inflammation with increased expression of NF- $\mathrm{KB}$ and cytokine responses in a mouse model [169]. Overall, gut microbiome dysbiosis and subsequent endotoxemia represent a supplementary pathophysiological explanation for increased COVID-19 severity in obesity. Modulation of the gut microbiota could positively impact COVID-19 disease progression. More studies are needed to explore whether altering the gut microbiota through diet might be a feasible adjunct to the COVID-19 treatment armamentarium.

\section{Mechanical Issues Related to Obesity and Physical Inactivity}

Individuals with obesity present mechanical issues associated with excess weight. In particular, health care and prognosis in patients with obesity and COVID-19 are affected due to (i) the difficulties of insertions of vascular catheters and intubation attributed to excess adiposity; (ii) the lack of ICU facilities, such as bariatric hospital beds, to accommodate patients with severe obesity; (iii) the challenges encountered to obtain a proper imaging diagnosis; (iv) the poor mobility of patients with obesity; and (v) the difficulties to transport and position (e.g., prone positioning) patients with obesity by the nursing staff $[170,171]$.

Moreover, a large WC restricts thoracic expansion with suppression of the lung parenchyma at the lung bases, resulting in compromised lung ventilation and the decrease of oxygen supply [172]. In a large study, greater respiratory disease severity, such as severe hypoxemia and higher prevalence of radiographic abnormalities on chest X-ray, was observed in patients with obesity [12••]. Decreased functional respiratory capacity, pulmonary expiratory reserve volume, and respiratory system compliance are also included in the adverse respiratory mechanical factors observed in obesity. Interestingly, the increased thoracic mass could play an important role for higher positive end-expiratory and peak pressures to maintain adequate oxygenation in mechanically ventilated patients with obesity in comparison to patients with normal weight $[12 \cdot \bullet]$.

In addition to adverse respiratory mechanical factors, subjects with obesity often present hiatus hernia with gastroesophageal reflux disease which could affect appropriate absorption of orally administered drugs [65]. Overall, all these physical/mechanical features may complicate the clinical course of patients with obesity and COVID-19.

Furthermore, physical inactivity and sarcopenia due to the loss of muscle mass may contribute to altered immune responses in obesity, particularly leptin response and the delay in type I IFN responsiveness to infection [65]. Very few studies have addressed the independent association of physical inactivity with COVID-19 outcomes. In a community-based cohort study of 387,109 adults from the UK Biobank, physical inactivity (RR: $1.32,95 \%$ CI: 1.10-1.58), smoking (RR: 1.42, 95\% CI: $1.12-1.79$ ), and obesity (RR: $2.05,95 \%$ CI: 1.68 2.49 ) but not heavy alcohol consumption (RR: $1.12,95 \% \mathrm{CI}$ : 0.93-1.35) were related to increased risk of hospitalization due to COVID-19 after adjusting for age and gender and mutually for each lifestyle factor [173]. In a Mendelian randomization study of 941,280 individuals of European ancestry conducted by the COVID-19 Host Genetic Initiative, a perSD increase in genetically predicted physical activity was associated with a lower risk of severe respiratory COVID-19 (OR: 0.19, 95\% CI: 0.05-0.74) but not with COVID-19 hospitalization (OR: 0.44, 95\% CI: 0.18-1.07) [174]. These studies highlight the importance of maintaining a healthy lifestyle in lowering the risk of severe COVID-19.

\section{Psychological Issues in Obesity}

Obesity presents a bidirectional association with mental health disorders [175], such as depression and anxiety, which are often exacerbated by the stigma experienced by some individuals with obesity as a result of their excess weight. Obesity is a frequently stigmatized somatic characteristic. There is significant empirical evidence that individuals with obesity elicit negative feelings such as anger, disgust, blame, and dislike in others [176]. Subjects with obesity are commonly the targets of derogatory comments, prejudice, and other poor treatment in many settings, including health care [176]. Moreover, there is mounting evidence that physicians, nurses, medical students, and other health care professionals have negative opinions about individuals with obesity [176-178]. 
Experiences of discrimination and awareness of stigmatized status may increase stress in patients. Other consequences include avoidance of clinical care when patients perceive that their excess body weight could be a source of embarrassment in the hospital setting [179]. Elevated BMI has been associated with lower utilization of health care [180]. The long-term implication of avoidance and postponement of health care is that individuals with obesity may present with more advanced and difficult to treat conditions [176]. In particular, subjects with obesity and COVID-19 may delay seeking medical care and follow up, attributed to the fear of being stigmatized, increasing the risk of severe COVID-19 and mortality [7]. The portrayal of obesity by media has been recognized as one of the most significant factors for the development and maintenance of weight stigma attitudes and discriminatory behavior [181]. Interestingly, as news sources underscore obesity as a risk factor for severe COVID-19, individuals with obesity may delay seeking care due to the perceived stigma and personal vulnerability [180]. As a result, people with obesity do not feel welcome in the health care environment.

Moreover, clinic equipment often designed for use with patients of smaller weight, such as waiting room chairs, hospital beds, scales, blood pressure cuffs, and examination gowns, could also promote identity threat for patients with obesity [176]. All the abovementioned factors are important for all health care issues related to obesity but are particularly highlighted in the context of the COVID-19 pandemic. Weight stigma represents one significant missing link between obesity and the risk of critical COVID-19 that requires a further emphasis on research and clinical practice. Collectively, health care avoidance due to weight stigma may act synergistically with any underlying pathogenetic mechanism to severe infection and mortality amid patients with obesity and COVID-19.

\section{Racial/Ethnic Disparities in Nutrition and Obesity in the Context of COVID-19 Pandemic}

The severity of COVID-19 in subjects with obesity may explain the disproportionate toll of the pandemic in some communities. For example, Black, Latino, and Native Americans and other minority groups are experiencing higher rates of infections, poor outcomes, and deaths from COVID-19 than non-Hispanic White subjects. All these minority groups face obstacles in accessing health, social services, education, and affordable, healthy food [182••]. These disparities combine to render also rates of obesity remarkably high in these groups. Indeed, the biggest increases in the prevalence of obesity were shown amid Mexican American men and Black and Mexican American women compared with non-Hispanic White men and women [152]. Poor diet in conjunction with smoking are amid the prevailing underlying causes of death. The ability to eat a healthy diet, low in sugar and processed foods but rich in fruits, vegetables, nuts, and fish, depends on access to affordable healthy nutrients. For example, children living in racially segregated communities are prone to develop obesity due to barriers to accessing high-quality, nutritious food and poor walkability. Interestingly, health inequalities in nutrition and obesity correlate significantly with the racial and ethnic disparities associated with SARS-CoV-2 infection. The ageadjusted hospitalization rates due to COVID-19 are approximately 5 and 4.5 times greater in Native Americans and Black Americans, respectively, compared to those of White Americans [182•0]. The Bronx borough of New York (where Black and Latino mainly reside), which displays elevated rates of obesity and associated disorders attributed to the higher levels of poverty and food insecurity, has presented elevated rates of hospitalizations and mortality related to COVID-19 [183]. The parallel rise of obesity and COVID-19 within racial and ethnic groups may reflect a complex interplay of contributing parameters that are stemming from the social determinants of health which include, among others, socioeconomic status, racism and ethnic discrimination, access to health services, healthy food, and education, the geographic location, and social and community contexts $[182 \bullet \cdot]$.

\section{Implications in Prevention and Treatment}

Table 3 summarizes the implications in the prevention and therapeutic management of COVID-19 in patients with obesity and obesity-associated metabolic disorders. Individuals with obesity, particularly young adults, are at higher risk for severe COVID-19, IMV if hospitalized, and mortality [12••]. These important findings support clear public health messaging and rigorous compliance to COVID-19 prevention strategies in subjects with obesity of all ages.

Besides general measures regarding prevention of the risk of infection such as wearing masks, social distancing and regular hand washing, adoption of a healthy lifestyle with a diet characterized by less consumption of ultraprocessed foods and beverages, and more consumption of vegetables, legumes, fresh fruits, and selected whole grains is of paramount importance. A significant change in dietary habits has occurred during the COVID-19 pandemic. Interestingly, a large Italian population study has documented that during the first lockdown, almost one third of the participants consumed less healthy foods, while half of them reported weight gain [184]. It is possible that stay-at-home policies in conjunction with social distancing may exacerbate weight gain via their effects on physical activity and diet patterns. Current data and expert opinion highlight the significance of vitamins D and C, minerals such as zinc, nutraceuticals such as curcumin, and 
Table 3 Special considerations in the prevention and therapeutic management of COVID-19 in patients with obesity and associated metabolic disorders

\begin{tabular}{|c|c|}
\hline Intervention/Risk & Problems/Considerations \\
\hline \multicolumn{2}{|l|}{ Preventive measures } \\
\hline General measures & $\begin{array}{l}\checkmark \uparrow \text { risk for severe COVID-19, IMV if hospitalized and } \\
\text { mortality in individuals with obesity }\end{array}$ \\
\hline $\begin{array}{l}\text { Adoption of a healthy } \\
\text { lifestyle and diet }\end{array}$ & $\begin{array}{l}\checkmark \text { A healthy and balanced diet strengthens the immune } \\
\text { system }\end{array}$ \\
\hline Physical exercise & $\checkmark$ Regular physical activity strengthens the immune system \\
\hline $\begin{array}{l}\text { Optimal metabolic } \\
\text { control }\end{array}$ & $\begin{array}{l}\checkmark \downarrow \text { Morbidity and } \downarrow \text { mortality with optimal metabolic } \\
\text { control in patients with obesity and T2DM }\end{array}$ \\
\hline $\begin{array}{l}\text { Vitamin D } \\
\text { supplementation }\end{array}$ & $\begin{array}{l}\checkmark \uparrow \text { risk of severe COVID-19 with vitamin D deficiency } \\
\text { Lower serum } 25 \text { OHD in patients with obesity }\end{array}$ \\
\hline Influenza vaccination & $\begin{array}{l}\checkmark \downarrow \text { Outpatient visits associated with influenza } \\
\checkmark \downarrow \text { Risk of simultaneous coinfection }\end{array}$ \\
\hline $\begin{array}{l}\text { Vaccination against } \\
\text { SARS-CoV-2 }\end{array}$ & $\begin{array}{l}\checkmark \text { Obesity, particularly severe obesity, among priorities for } \\
\text { vaccination }\end{array}$ \\
\hline \multicolumn{2}{|l|}{ Outpatient management } \\
\hline $\begin{array}{l}\text { Optimal metabolic } \\
\text { control }\end{array}$ & $\begin{array}{l}\checkmark \downarrow \text { Severe COVID-19 and mortality with optimal } \\
\text { metabolic/glycemic control in patients with obesity and } \\
\text { T2DM }\end{array}$ \\
\hline $\begin{array}{l}\text { Utilization of telehealth } \\
\text { visits }\end{array}$ & $\checkmark \uparrow$ Utilization of telemedicine services should be promoted \\
\hline $\begin{array}{l}\text { Monitoring of oxygen } \\
\text { saturation, heart rate and } \\
\text { blood pressure }\end{array}$ & $\begin{array}{l}\checkmark \text { Normal } \mathrm{SpO}_{2} \text { is } \geq 95 \% \text {. Some patients with chronic lung } \\
\text { disease or sleep apnea, which is often associated with } \\
\text { obesity, may have levels } \approx 90 \% \text {. }\end{array}$ \\
\hline
\end{tabular}

Recommendations

$\checkmark$ Wearing mask, regular hand washing, and social distancing based on WHO and CDC guidelines

$\checkmark$ Rigorous compliance to COVID-19 prevention strategies in subjects with obesity

$\checkmark$ Weight loss

$\checkmark \downarrow$ Sedentary living

$\checkmark \downarrow$ Consumption of processed foods and beverages

$\checkmark \uparrow$ Consumption of vegetables, legumes, fresh fruits and selected whole grains

$\checkmark$ Continuation of moderate physical activity

$\checkmark$ Optimal metabolic/glycemic control in patients with obesity and T2DM

$\checkmark$ Vitamin D supplementation to maintain circulating $25 \mathrm{OHD}$ within the optimal levels $(75-125 \mathrm{nmol} / \mathrm{L})$

$\checkmark$ Optimal metabolic control in patients with obesity and T2DM

$\checkmark$ FPG $\leq 6.1 \mathrm{mmol} / \mathrm{L}$ and $2 \mathrm{~h}$ postprandial glucose $\leq 7.8$ $\mathrm{mmol} / \mathrm{L}$ for non-senile DM patients with mild COVID-19

$\checkmark$ FPG $\leq 7.8 \mathrm{mmol} / \mathrm{L}$ and $2 \mathrm{~h}$ postprandial glucose $\leq 10$ $\mathrm{mmol} / \mathrm{L}$ for older DM patients with mild COVID-19

$\checkmark$ CDC defines severe COVID-19 in people who have respiratory frequency $>30$ breaths per minute, $\mathrm{SpO}_{2}<$ $94 \%$ on room air at sea level (or, for patients with chronic hypoxemia, a decrease from baseline of $>3 \%$ )

$\checkmark$ Refer for further evaluation and possible treatment if $\mathrm{SpO}_{2}$ reading is below baseline

Pharmacotherapy in COVID-19

Metabolic/Glycemic control

Remdesivir

Monoclonal antibody therapy with bamlanivimab or REGN-COV2 $\checkmark$ Improved outcomes with optimal glycemic control during hospitalization

$\checkmark \downarrow$ AKI, DIC, ARDS, septic shock, acute cardiac dysfunction

$\checkmark$ Potential risks in patients with obesity and fatty liver disease

$\checkmark$ Potential risk of hyperglycemia

$\checkmark$ Risk of hyperglycemia and susceptibility to infections

$\checkmark$ Not authorized for patients who are hospitalized or require oxygen therapy due to COVID-19
Individualized glycemic goals based on age, comorbidities, and the severity of infection

$\checkmark$ FPG levels $\leq 10 \mathrm{mmol} / \mathrm{L}$ or postprandial/random levels $\leq$ $13.9 \mathrm{mmol} / \mathrm{L}$ may be acceptable for older patients hospitalized with severe COVID-19

$\checkmark$ Administration in hospitalized patients with severe COVID-19

$\checkmark$ Not recommended in patients with ALT $\geq 5 \times$ the upper limit of normal

$\checkmark$ Not recommended in patients with eGFR $<30 \mathrm{~mL} / \mathrm{min}$ per $1.73 \mathrm{~m}^{2}$

$\checkmark$ Administration in severe COVID-19

$\checkmark$ For the treatment of mild-to-moderate COVID-19 in adult and pediatric patients who are at high risk for progressing to severe COVID-19 and/or hospitalization, including those who are $\geq 65$ years of age or who have certain chronic medical conditions including patients with $\mathrm{BMI} \geq$ $35 \mathrm{~kg} / \mathrm{m}^{2}$ and cardiometabolic disorders 
Table 3 (continued)

\begin{tabular}{|c|c|c|}
\hline Intervention/Risk & Problems/Considerations & Recommendations \\
\hline Anti-coagulants & $\begin{array}{l}\checkmark \uparrow \text { Endothelial dysfunction and hypercoagulable state in } \\
\text { obesity }\end{array}$ & $\begin{array}{l}\checkmark \text { Pharmacologic prophylaxis for thromboembolic events in } \\
\text { patients with cardiometabolic risk factors in the absence } \\
\text { of contraindications }\end{array}$ \\
\hline Anakinra (anti-IL-1R) & $\checkmark$ Used in the cytokine storm of severe COVID-19 & \\
\hline Tocilizumab (anti-IL-6) & $\begin{array}{l}\checkmark \text { Optimal COVID-19 infection management with TCZ is } \\
\text { not achieved during hyperglycemia in both diabetic and } \\
\text { nondiabetic patients }\end{array}$ & \\
\hline \multicolumn{3}{|c|}{ Pharmacotherapy in associated metabolic disorders } \\
\hline Statins & $\begin{array}{l}\checkmark \uparrow \text { ACE2 levels in murine models } \\
\checkmark \downarrow \text { Odds of mortality from } \\
\checkmark \text { COVID-19 amid statin users } \\
\checkmark \text { Anti-inflammatory actions }\end{array}$ & Continuation of treatment ${ }^{\star}$ \\
\hline ACE inhibitors/ARBs & $\begin{array}{l}\checkmark \text { Previous debate on } \uparrow \text { risk of SARS-CoV-2 infection } \\
\text { susceptibility due to the } \uparrow \text { ACE } 2\end{array}$ & $\begin{array}{l}\checkmark \text { Continuation of treatment in the absence of } \\
\text { contraindications }\end{array}$ \\
\hline GLP-1R agonists & $\begin{array}{l}\checkmark \text { Potential dehydration risk due to gastrointestinal adverse } \\
\text { effects } \\
\checkmark \text { Beneficial anti-inflammatory, anti-obesogenic, } \\
\text { insulin-sensitizing, and cardioprotective actions }\end{array}$ & $\begin{array}{l}\checkmark \text { Discontinuation in severe COVID-19 } \\
\checkmark \text { Regular meals and maintenance of fluid intake }\end{array}$ \\
\hline Metformin & $\begin{array}{l}\checkmark \text { Risk of AKI } \\
\checkmark \text { Risk of lactic acidosis in severe COVID-19 with } \\
\text { hemodynamic instability and hypoxia } \\
\checkmark \uparrow \text { Risk of hypoglycemia and adverse gastrointestinal } \\
\text { effects with the use of hydroxychloroquine and } \\
\text { chloroquine } \\
\checkmark \text { Anti-inflammatory actions, } \downarrow \text { serum inflammatory } \\
\text { biomarkers }\end{array}$ & $\begin{array}{l}\checkmark \text { Monitoring of renal function } \\
\checkmark \text { Discontinuation in severe COVID-19 }\end{array}$ \\
\hline $\begin{array}{l}\text { PPAR- } \gamma \text { agonists } \\
\text { (pioglitazone) }\end{array}$ & $\begin{array}{l}\checkmark \text { Improvement of hepatic steatosis and inflammation } \\
\checkmark \text { Insulin-sensitizing and anti-inflammatory actions }\end{array}$ & $\begin{array}{l}\checkmark \text { Discontinuation in patients with severe COVID-19 if } \\
\text { presence of fluid retention and worsening of heart failure }\end{array}$ \\
\hline DPP-4 inhibitors & $\begin{array}{l}\checkmark \text { Beneficial effects in MERS as DPP4 receptor is a } \\
\text { functional MERS-CoV target } \\
\checkmark \text { Potential beneficial effects in COVID-19??? }\end{array}$ & $\begin{array}{l}\checkmark \text { Good safety profile } \\
\checkmark \text { Continuation in mild COVID-19 cases }\end{array}$ \\
\hline SGLT2 inhibitors & $\begin{array}{l}\checkmark \downarrow \text { Complications and mortality in hospitalized patients } \\
\text { with mild-moderate COVID-19 with risk factors for } \\
\text { severe complications (DARE-19) } \\
\checkmark \text { Risk of euglycemic DKA exacerbated by dehydration and } \\
\downarrow \text { insulin } \\
\checkmark \text { Preservation of CV and renal function is important for } \\
\text { favorable outcomes in patients with obesity and T2DM }\end{array}$ & $\begin{array}{l}\checkmark \text { Maintenance in mild COVID-19 due to nephroprotective } \\
\text { and cardioprotective potential }\end{array}$ \\
\hline Insulin & $\begin{array}{l}\checkmark \text { Monitoring of serum } \mathrm{K}^{+} \text {levels for the prevention of } \\
\text { hypokalemia } \\
\checkmark \uparrow \text { Insulin in hospitalized patients with severe } \\
\text { hyperglycemia and/or DKA } \\
\checkmark \text { Risk of hypoglycemia }\end{array}$ & $\begin{array}{l}\checkmark \text { Continuation of treatment } \\
\checkmark \text { Frequent monitoring of blood glucose } \\
\checkmark \text { Dose adjustment depending on glycemic control, severity } \\
\text { of COVID-19, and the use of other drugs }\end{array}$ \\
\hline $\begin{array}{l}\text { Patients with obesity and } \\
\text { underlying fatty liver } \\
\text { disease }\end{array}$ & $\begin{array}{l}\checkmark \text { Risk of cytokine storm } \\
\checkmark \text { Remdesivir is not recommended in patients with ALT } \geq \\
5 \times \text { the upper limit of normal }\end{array}$ & $\begin{array}{l}\checkmark \text { Close monitoring of hepatic transaminases, prothrombin } \\
\text { time, fibrinogen, ferritin, CRP, ESR, IL-6, and D-Dimer }\end{array}$ \\
\hline Risk of diabetes & $\begin{array}{l}\checkmark \text { Potential } \uparrow \text { risk of T2DM in COVID-19 patients as shown } \\
\text { in the previous pandemic of SARS where hospitalized } \\
\text { patients without steroid treatment and hx of T2DM } \\
\text { developed T2DM }\end{array}$ & $\begin{array}{l}\checkmark \text { HbA1c should be assessed in patients with COVID-19 } \\
\text { with hyperglycemia and/or ketoacidosis to identify } \\
\text { potential undiagnosed DM }\end{array}$ \\
\hline
\end{tabular}

‡ Position statement by the European Society of Cardiology, the American College of Cardiology, the American Heart Association, and the Heart Failure Society of America

$A C E$, angiotensin-converting enzyme; $A K I$, acute kidney injury; $A L T$, alanine aminotransferase; $A R B s$, angiotensin receptor blocker; $C D C$, Centers for Disease Control and Prevention; $C R P$, C-reactive protein; $C V$, cardiovascular; $D I C$, disseminated intravascular coagulation; $D K A$, diabetic ketoacidosis; $D M$, diabetes mellitus; $D P P-4$, dipeptidyl peptidase 4; $e G F R$, estimated glomerular filtration rate; $E S R$, erythrocyte sedimentation rate; $G L P-1 R$, glucagon-like peptide 1 receptor; $I L$, interleukin; MERS, Middle East respiratory syndrome; $P P A R-\gamma$, peroxisome proliferator-activated receptors- $\gamma$; $S G L T 2$ : sodium glucose co-transporter 2; TCZ, tocilizumab 
the maintenance of adequate hydration, proposing also moderate consumption of fat, preferably unsaturated fats, and avoidance of salt and sugar intake [94, 185, 186]. The Mediterranean diet represents one of the healthiest dietary approaches globally, recognized for its demonstrated preventive actions in T2DM and cardiometabolic disorders in a plethora of trials [187]. Compliance with the Mediterranean diet which presents anti-inflammatory, anti-oxidant, and immunomodulatory properties may influence the course of cardiometabolic disorders including obesity that predisposes to severe COVID-19 [105, 188]. Furthermore, regular physical activity and weight loss are positively related to favorable outcomes in cardiometabolic disorders and immunologic health (immune activation, immune modulation of inflammation, and vaccination efficacy) [65]. Interestingly, prior metabolic surgery with subsequent weight loss and improvement of metabolic abnormalities was related to decreased rates of hospitalizations, admissions in the ICU, and mortality in patients with obesity who became infected with SARS-CoV-2 [189-191].

More than 10 trials on vitamin D supplementation and COVID-19 are registered on the ClinicalTrials.gov website. Nevertheless, it is still uncertain whether vitamin D supplementation may decrease the risk of severe SARSCoV-2 infection. Although vitamin D deficiency was not linked to a higher risk of COVID-19, severity and mortality of COVID-19 were associated with lower vitamin D levels [156]. Hence, individuals with obesity who are at higher risk of vitamin D deficiency during this pandemic may consider taking vitamin D supplements to maintain circulating $25(\mathrm{OH})$ D within the optimal levels (75-125nmol/L) [192].

Emphasis is also placed on influenza vaccination during the 2020-2021 influenza season because it coincides with the circulation of SARS-CoV-2. Symptoms of COVID-19 and influenza cannot be distinguished without specific tests for both viruses. Vaccination against influenza will reduce the need for outpatient visits associated with influenza and decrease the unclear risk of simultaneous coinfection with both viruses.

Obesity is a priority for the vaccination against SARS$\mathrm{CoV}-2$. Individuals with severe obesity (BMI $\geq 40 \mathrm{~kg} / \mathrm{m}^{2}$ ) should be considered high risk for severe COVID-19 infection and may warrant prioritization for a COVID-19 vaccine [12••]. However, it is important to mention that subjects with obesity present lower antibody levels, a weaker influenzaspecific CD8+ T-cell function, and 2 and 3 times increased incidence of influenza despite vaccination in comparison to normal-weight subjects [69].

Maximal utilization of telemedicine services should be promoted along with frequent self-monitoring of blood glucose. Through continuous daily remote monitoring of patients with obesity and asymptomatic or mild-moderate COVID-19, physicians may intervene timely in cases of deterioration in vital signs and symptoms, referring the patient to the hospital [193]. Of note, advances in biosensor technologies rendered possible the continuous monitoring of physiologic factors using wearable biosensors detecting a variety of parameters, such as blood oxygen saturation, skin temperature, respiratory rate, blood pressure, pulse rate, and daily activities [194]. Despite issues regarding accuracy, monitoring arterial oxygenation through pulse oximetry at home by pocket oximeters and smart phone-based systems may prove beneficial in reducing complications associated with severe infection by detecting early severe hypoxemia in the absence of dyspnea, a problem unofficially referred to as "silent hypoxemia" [194].

Optimal metabolic control in patients with obesity and T2DM is important in both outpatient and inpatient therapeutic management, preventing hospitalization, severe COVID19, and complications [53, 155]. Hemoglobin A1c should be determined in patients with obesity who exhibit hyperglycemia and/or ketoacidosis to reveal potential undiagnosed diabetes [2•]. Continuation of treatment with oral antidiabetic agents depends on the risk of severe COVID-19 and the general health status of the patients [195]. Metformin has shown anti-inflammatory effects, decreasing inflammatory biomarkers and reducing the mortality rate from COVID-19 infection. However, it presents the risk of acute kidney injury (AKI) and lactic acidosis in severe COVID-19. Glucagon-like peptide-1 (GLP-1) agonists present beneficial anti-inflammatory, anti-obesogenic, and metabolic properties among subjects with T2DM and obesity [53]. Besides ACE2, dipeptidyl peptidase 4 (DPP4), a functional target of MERS-CoV, could serve as a binding target for SARS-CoV-2; nevertheless, preliminary data do not suggest a notable effect of DPP4 inhibitors on SARS-CoV-2 susceptibility [196]. DPP4 inhibitors exhibit a good safety profile and can be continued based on the patient's tolerance [197]. Sodium-glucose cotransporter-2 (SGLT-2) inhibitors might provoke side effects in patients with severe COVID-19, increasing the risk of dehydration and euglycemic diabetic ketoacidosis (DKA); thus, there are published recommendations supporting the discontinuation of these drugs among patients with severe COVID-19 to reduce the risk of acute metabolic decompensation [53, 196]. Lastly, patients who take insulin at home as a last resort must be encouraged to continue adjusting the dose based on their blood glucose levels.

Therapy with statins and antihypertensive agents can be continued in patients with obesity and dyslipidemia or hypertension, respectively. Whether upregulation of ACE2 by ACE inhibitors or angiotensin-receptor blockers (ARBs) increases the risk of SARS-CoV-2 infection or is protective against ARDS has been extensively debated. A position statement from the American and European cardiovascular societies recommended the continuation of ACE inhibitors/ARBs in patients with COVID-19 if there is no other reason for discontinuation (e.g., hypotension, AKI) [198]. 
Patients with obesity and T2DM with MAFLD may present an elevated risk for experiencing a cytokine storm; therefore, it is necessary to monitor closely the transaminases, Creactive protein, IL-6, D-dimer, ferritin, fibrinogen, prothrombin time, fibrinogen, and lymphocyte count [199-201]. If available, remdesivir is suggested for hospitalized patients with severe COVID-19. Remdesivir, which was recently approved by the FDA for hospitalized adults and pediatric patients above 12 years of age and weighing at least $40 \mathrm{~kg}$ for the treatment of COVID-19, is not recommended when serum alanine aminotransferase (ALT) are 5 times the upper limit of normal and should be discontinued if ALT rises above this level during treatment [202-205]. The pharmacokinetics of remdesivir in the setting of renal insufficiency is unclear. Therefore, remdesivir is not recommended in patients with an estimated glomerular filtration rate $<30 \mathrm{~mL} / \mathrm{min}$ per 1.73 $\mathrm{m}^{2}$. Health care providers should bear in mind the possibility of hyperglycemia with the administration of remdesivir in patients with T2DM and obesity [205].

Evidence from a large trial that has recently been published by the RECOVERY Collaborative Group advocates the use of dexamethasone in the management of severe COVID-19 (i.e., patients who are on supplemental oxygen or IMV), showing a reduction in mortality by $8-25 \%$ [111 ••]. Potential side effects of glucocorticoids in severely ill patients with obesity and T2DM include hyperglycemia and susceptibility to other infections, including bacterial, fungal, and Strongyloides infections. Furthermore, due to the increased thromboembolic risk, particularly in obesity, published evidence has supported the administration of therapeutic anticoagulants such as lowmolecular-weight heparin in the inpatient setting, especially in the ICU $[2 \bullet, 7,206]$. However, the optimal dose in anticoagulation is an area of active investigation. Whether thromboprophylaxis should be employed in nonhospitalized patients with COVID-19, who present risk factors for thrombosis, such as obesity, is a pressing question. The PREVENTHD trial is actually evaluating this issue [207].

In November 2020, the FDA issued emergency use authorizations for the investigational monoclonal antibody therapy bamlanivimab (November 9, 2020) and REGN-COV2, a combination of two monoclonal antibodies casirivimab and imdevimab (November 21, 2020), for the treatment of mildto-moderate COVID-19 in adult and pediatric patients who are at high risk for progressing to severe COVID-19 and/or hospitalization $[208,209]$. These include those who are $\geq 65$ years of age or who have certain chronic medical conditions including patients with $\mathrm{BMI} \geq 35 \mathrm{~kg} / \mathrm{m}^{2}$ and cardiometabolic disorders, i.e., diabetes, hypertension, and CVD. Monoclonal antibody therapy is not authorized for patients who are hospitalized or require oxygen therapy due to COVID-19. While the effectiveness and safety are being evaluated, monoclonal antibody therapy was shown in clinical trials to decrease COVID-19-related hospitalization or emergency room visits in patients at high risk for disease progression within 28 days after treatment when compared to placebo.

Finally, it is important to mention that patients with obesity are often excluded from clinical trials [7]. Historically, individuals with increased BMI have been underrepresented from drug trials due to the coexistence of related chronic conditions (i.e., diabetes, CVD) that may obscure the results of the trials $[210,211]$. However, the clinical trials to test the safety and efficacy of coronavirus vaccines did not have exclusion criteria based on BMI $[212,213]$. There is a need to enroll individuals with higher BMI in COVID-19 treatment trials to learn more about the efficacy and safety of treatments as well as pharmacokinetics and therapeutic dosages.

\section{Conclusions}

Obesity and increased visceral adiposity have emerged as significant risk factors for adverse outcomes associated with COVID-19. Potential mechanisms, through which the excess adipose tissue provides the ideal conditions for enhanced viral pathogenesis leading to severe COVID-19, include (i) impaired innate and adaptive immune responses; (ii) chronic inflammation and oxidative stress; (iii) endothelial dysfunction, hypercoagulability, and aberrant activation of the complement; (iv) overactivation of the RAAS; (v) overexpression of ACE2 in the adipose tissue; (vi) associated cardiometabolic comorbidities; (vii) vitamin D deficiency; (viii) gut dysbiosis; and (ix) mechanical and psychological issues. Evidence from geographic and ethnic variations affecting susceptibility to SARS-CoV-2 infection may shed light on the hidden links between dysregulated metabolism and worse outcomes. Mechanistic and large epidemiologic studies using big data sources with omics data exploring genetic determinants of risk and disease severity as well as large RCTs are necessary to delineate pathways connecting chronic subclinical metainflammation with adverse COVID-19 outcomes and establish the ideal preventive therapeutic approaches for patients with obesity.

Abbreviations ACE, angiotensin-converting enzyme; AHA, American Heart Association; AKI, acute lung injury; ALI, acute lung injury; ALT, alanine transaminase; ARBs, angiotensin receptor blockers; ARDS, acute respiratory distress syndrome; AT1R, angiotensin 1 receptor; AT2, alveolar type 2 pneumocytes; BMI, body mass index; CFR, case fatality rate; $\mathrm{CI}$, confidence interval; $\mathrm{CKD}$, chronic kidney disease; COPD, chronic obstructive pulmonary disease; COVID-19, coronavirus disease 2019; CVD, cardiovascular disease; CXCL10, CXC-chemokine ligand 10; DKA, diabetic ketoacidosis; DPP-4, dipeptidyl-dipeptidase 4; FDA, Food and Drug Administration; FEV1, forced expiratory volume in one second; GLP-1, glucagon-like peptide-1; ICU, intensive care unit; IFN, interferon; IFR, infection fatality rate; IL, interleukin; IMV, invasive mechanical ventilation; LPS, lipopolysaccharide; MAFLD, metabolic associated fatty liver disease; MAS, macrophage activation syndrome; $\mathrm{MCP}$ 1, monocyte chemoattractant protein-1; MERS, Middle East respiratory 
syndrome; MIP1- $\alpha$, macrophage inflammatory protein $1-\alpha$; NHANES, National Health and Nutrition Examination Survey; NF-kB, nuclear factor- $\mathrm{KB}$; NK, natural killer; NLRP3, NOD-like receptor family pyrin domain containing 3; NO, nitric oxide; NOS, nitric oxide synthase; OR, odds ratio; PAI-1, plasminogen activator inhibitor-1; PI3K, phosphoinositide 3-kinase; RAAS, renin-angiotensin-aldosterone system; RCTs, randomized controlled trials; RR, relative risk; SARS-CoV2 , severe acute respiratory syndrome coronavirus 2 ; SD, standard deviation; SGLT-2 inhibitors, sodium glucose transporter-2 inhibitors; T2DM, type 2 diabetes mellitus; TLRs, toll-like receptors; TNF- $\alpha$, tumor necrosis factor- $\alpha$; VEGF, vascular endothelial growth factor; WC, waist circumference; WHO, World Health Organization; WHR, waist-to-hip ratio

Funding Professor C.M. Apovian is supported by a grant P30DK046200 from the Boston Obesity Nutrition Research Center.

\section{Declarations}

CMA reports receiving personal fees from Nutrisystem, Zafgen, SanofiAventis, Orexigen, EnteroMedics, GI Dynamics, Scientific Intake, Gelesis, Novo Nordisk, SetPoint Health, Xeno Biosciences, Rhythm Pharmaceuticals, Eisai, and Takeda outside of the funded work. CMA reports receiving grant funding from Aspire Bariatrics, GI Dynamics, Orexigen, Takeda, the Vela Foundation, Gelesis, Energesis, Coherence Lab, and Novo Nordisk outside of the funded work. CMA reports past equity interest in ScienceSmart, LLC. No other disclosures were reported.

Human and Animal Rights and Informed Consent This article does not contain any studies with human or animal subjects performed by any of the authors.

Conflict of Interest All authors declare that they have no conflict of interest.

\section{References}

Papers of particular interest, published recently, have been

highlighted as:

- Of importance

•• Of major importance

1. https://covid19.who.int/. Accessed 18 Dec 2020.

2. Gupta A, Madhavan MV, Sehgal K, Nair N, Mahajan S, Sehrawat TS, et al. Extrapulmonary manifestations of COVID-19. Nat Med. 2020;26:1017-32. https://doi.org/10.1038/s41591-020-0968-3 This review highlights the extrapulmonary organ-specific pathophysiology, presentations and management considerations for patients with COVID-19 in order to help clinicians and scientists in recognizing and monitoring the spectrum of manifestations.

3. Scudellari M. How Iceland hammered COVID with science. Nature. 2020;587:536-9. https://doi.org/10.1038/d41586-02003284-3.

4. Obesity. 2020. https://www.who.int/health-topics/obesity. Accessed 18 Dec 2020.

5. Hales CM, Carroll MD, Fryar CD, Ogden CL. Prevalence of obesity and severe obesity among adults: United States, 2017-2018. 2020. NCHS Data Brief, no 360. Hyattsville, MD: National Center for Health Statistics.
6. Kelly T, Yang W, Chen CS, Reynolds K, He J. Global burden of obesity in 2005 and projections to 2030. Int J Obes. 2008;32: 1431-7. https://doi.org/10.1038/ijo.2008.102.

7. Wadman M. Why obesity worsens COVID-19. Science. 2020;369:1280-1. https://doi.org/10.1126/science.369.6509. 1280.

8. Hill MA, Sowers JR, Mantzoros CS. Commentary: COVID-19 and obesity pandemics converge into a syndemic requiring urgent and multidisciplinary action. Metabolism. 2020;114:154408. https://doi.org/10.1016/j.metabol.2020.154408.

9. Obesity and overweight. 2020. https://www.who.int/news-room/ fact-sheets/detail/obesity-and-overweight. Accessed 18 December 2020.

10. Chooi YC, Ding C, Magkos F. The epidemiology of obesity. Metabolism. 2019;92:6-10. https://doi.org/10.1016/j.metabol. 2018.09.005.

11. Rizzo S, Chawla D, Zalocusky K, Keebler D, Chia J, Lindsay L et al. Descriptive epidemiology of 16,780 hospitalized COVID-19 patients in the United States. 2020:2020.07.17.20156265. 10.1101/2020.07.17.20156265 \%J medRxiv. https://doi.org/10. $1101 / 2020.07 .17 .20156265$

12.• Hendren NS, de Lemos JA, Ayers C, Das SR, Rao A, Carter S, et al. Association of Body mass index and age with morbidity and mortality in patients hospitalized with COVID-19: results from the American Heart Association COVID-19 Cardiovascular Disease Registry. Circulation. 2021;143:135-44. https://doi.org/ 10.1161/circulationaha.120.051936 In this American Heart Association's COVID-19 Cardiovascular Disease Registry, it was shown that patients with obesity are more likely to be hospitalized with COVID-19, and are at higher risk of inhospital death or mechanical ventilation, in particular, if young (age $\leq \mathbf{5 0}$ years).

13. Eastment MC, Berry K, Locke E, Green P, O'Hare A, Crothers K, et al. Body mass index (BMI) and outcomes of SARS-CoV-2 among US veterans. Obesity (Silver Spring). 2020. https://doi. org/10.1002/oby.23111.

14. Maffetone PB, Laursen PB. The Perfect storm: coronavirus (COVID-19) pandemic meets overfat pandemic. Front Public Health. 2020;8:135. https://doi.org/10.3389/fpubh.2020.00135.

15. Bhasin A, Nam H, Yeh C, Lee J, Liebovitz D, Achenbach C. Is BMI higher in younger patients with COVID-19? Association between BMI and COVID-19 hospitalization by age. Obesity (Silver Spring). 2020;28:1811-4. https://doi.org/10.1002/oby. 22947.

16. Kass DA, Duggal P, Cingolani O. Obesity could shift severe COVID-19 disease to younger ages. Lancet. 2020;395:1544-5. https://doi.org/10.1016/s0140-6736(20)31024-2.

17. Karampela I, Chrysanthopoulou E, Christodoulatos GS, Dalamaga M. Is There an obesity paradox in critical illness? Epidemiologic and metabolic considerations. Curr Obes Rep. 2020;9:231-44. https://doi.org/10.1007/s13679-020-00394-x.

18. Karampela I, Christodoulatos GS, Dalamaga M. The role of adipose tissue and adipokines in sepsis: inflammatory and metabolic considerations, and the obesity paradox. Curr Obes Rep. 2019;8: 434-57. https://doi.org/10.1007/s13679-019-00360-2.

19. Burn E, You SC, Sena AG, Kostka K, Abedtash H, Abrahão MTF, et al. An international characterisation of patients hospitalised with COVID-19 and a comparison with those previously hospitalised with influenza. medRxiv. 2020. https://doi.org/ 10.1101/2020.04.22.20074336.

20. Giannouchos TV, Sussman RA, Mier JM, Poulas K, Farsalinos K. Characteristics and risk factors for COVID-19 diagnosis and adverse outcomes in Mexico: an analysis of 89,756 laboratoryconfirmed COVID-19 cases. Eur Respir J. 2020. https://doi.org/ 10.1183/13993003.02144-2020. 
21. Gu T, Mack JA, Salvatore M, Sankar SP, Valley TS, Singh K, et al. COVID-19 outcomes, risk factors and associations by race: a comprehensive analysis using electronic health records data in Michigan Medicine. medRxiv. 2020. https://doi.org/10.1101/ 2020.06.16.20133140.

22. Reilev M, Kristensen KB, Pottegård A, Lund LC, Hallas J, Ernst MT, et al. Characteristics and predictors of hospitalization and death in the first 11122 cases with a positive RT-PCR test for SARS-CoV-2 in Denmark: a nationwide cohort. Int J Epidemiol. 2020. https://doi.org/10.1093/ije/dyaa140.

23. ICNARC report on COVID-19 in critical care. 2020. https://www. anhinternational.org/resources/documents/icnarc-covid-19report-2020-07-10/. Accessed 18 December 2020.

24.• Popkin BM, Du S, Green WD, Beck MA, Algaith T, Herbst CH, et al. Individuals with obesity and COVID-19: a global perspective on the epidemiology and biological relationships. Obes Rev. 2020;21:e13128. https://doi.org/10.1111/obr.13128 This metaanalysis has shown that obesity increases the risks of infection from SARS-CoV-2, severe infection and hospitalization, admission to the ICU and need of invasive mechanical ventilation as well as the risk of mortality.

25. Soeroto AY, Soetedjo NN, Purwiga A, Santoso P, Kulsum ID, Suryadinata H, et al. Effect of increased BMI and obesity on the outcome of COVID-19 adult patients: a systematic review and meta-analysis. Diabetes Metab Syndr. 2020;14:1897-904. https://doi.org/10.1016/j.dsx.2020.09.029.

26. Yang J, Tian C, Chen Y, Zhu C, Chi H, Li J. Obesity aggravates COVID-19: an updated systematic review and meta-analysis. J Med Virol. 2020. https://doi.org/10.1002/jmv.26677.

27. Leong A, Cole J, Brenner LN, Meigs JB, Florez JC, Mercader JM. Cardiometabolic risk factors for COVID-19 susceptibility and severity: a Mendelian randomization analysis. medRxiv. 2020. https://doi.org/10.1101/2020.08.26.20182709.

28. Singh S, Bilal M, Pakhchanian H, Raiker R, Kochhar GS, Thompson CC. Impact of obesity on outcomes of patients with coronavirus disease 2019 in the United States: a multicenter electronic health records network study. Gastroenterology. 2020;159: 2221-5.e6. https://doi.org/10.1053/j.gastro.2020.08.028.

29. Yanover C, Mizrahi B, Kalkstein N, Marcus K, Akiva P, Barer Y, et al. What factors increase the risk of complications in SARSCoV-2-infected patients? A cohort study in a nationwide Israeli health organization. JMIR Public Health Surveill. 2020;6:e20872. https://doi.org/10.2196/20872.

30. Petrilli CM, Jones SA, Yang J, Rajagopalan H, O'Donnell L, Chernyak Y, et al. Factors associated with hospital admission and critical illness among 5279 people with coronavirus disease 2019 in New York City: prospective cohort study. Bmj. 2020;369: m1966. https://doi.org/10.1136/bmj.m1966.

31.• Du Y, Lv Y, Zha W, Zhou N, Hong X. Association of Body mass index (BMI) with critical COVID-19 and in-hospital mortality: a dose-response meta-analysis. Metabolism. 2020:154373. https:// doi.org/10.1016/j.metabol.2020.154373 This meta-analysis has shown a linear dose-response association between BMI and both COVID-19 severity and mortality.

32. Chu Y, Yang J, Shi J, Zhang P, Wang X. Obesity is associated with increased severity of disease in COVID-19 pneumonia: a systematic review and meta-analysis. Eur J Med Res. 2020;25: 64. https://doi.org/10.1186/s40001-020-00464-9.

33. Bello-Chavolla OY, Bahena-López JP, Antonio-Villa NE, Vargas-Vázquez A, González-Díaz A, Márquez-Salinas A, et al. Predicting mortality due to SARS-CoV-2: a mechanistic score relating obesity and diabetes to COVID-19 outcomes in Mexico. J Clin Endocrinol Metab. 2020;105. https://doi.org/10.1210/ clinem/dgaa346.

34. Kim L, Garg S, O'Halloran A, Whitaker M, Pham H, Anderson EJ, et al. Risk factors for intensive care unit admission and in- hospital mortality among hospitalized adults identified through the U.S. coronavirus disease 2019 (COVID-19)-associated hospitalization surveillance network (COVID-NET). Clin Infect Dis. 2020. https://doi.org/10.1093/cid/ciaa1012.

35. Kaeuffer C, Ruch Y, Fabacher T, Hinschberger O, Mootien J, Eyriey M, et al. The BAS(2)IC score: a useful tool to identify patients at high risk of early progression to severe coronavirus disease 2019. Open Forum Infect Dis. 2020;7:ofaa405. https:// doi.org/10.1093/ofid/ofaa405.

36. Hamadah H, Alahmad B, Behbehani M, Al-Youha S, Almazeedi S, Al-Haddad M, et al. COVID-19 clinical outcomes and nationality: results from a nationwide registry in Kuwait. BMC Public Health. 2020;20:1384. https://doi.org/10.1186/s12889-02009490-y.

37. Földi M, Farkas N, Kiss S, Zádori N, Váncsa S, Szakó L, et al. Obesity is a risk factor for developing critical condition in COVID-19 patients: a systematic review and meta-analysis. Obes Rev. 2020;21:e13095. https://doi.org/10.1111/obr.13095.

38. Malik P, Patel U, Patel K, Martin M, Shah C, Mehta D, et al. Obesity a predictor of outcomes of COVID-19 hospitalized patients-a systematic review and meta-analysis. J Med Virol. 2020. https://doi.org/10.1002/jmv.26555.

39. Hajifathalian K, Kumar S, Newberry C, Shah S, Fortune B, Krisko $\mathrm{T}$, et al. Obesity is associated with worse outcomes in COVID-19: analysis of early data from New York City. Obesity (Silver Spring). 2020;28:1606-12. https://doi.org/10.1002/oby.22923.

40. Goyal P, Choi JJ, Pinheiro LC, Schenck EJ, Chen R, Jabri A, et al. Clinical characteristics of COVID-19 in New York City. N Engl J Med. 2020;382:2372-4. https://doi.org/10.1056/NEJMc2010419.

41. Argenziano MG, Bruce SL, Slater CL, Tiao JR, Baldwin MR, Barr RG, et al. Characterization and clinical course of 1000 patients with coronavirus disease 2019 in New York: retrospective case series. Bmj. 2020;369:m1996. https://doi.org/10.1136/bmj. m1996.

42. Baqui P, Bica I, Marra V, Ercole A, van der Schaar M. Ethnic and regional variations in hospital mortality from COVID-19 in Brazil: a cross-sectional observational study. Lancet Glob Health. 2020;8: e1018-e26. https://doi.org/10.1016/s2214-109x(20)30285-0.

43. Hussain A, Mahawar K, Xia Z, Yang W, El-Hasani S. Obesity and mortality of COVID-19. Meta-analysis. Obes Res Clin Pract. 2020;14:295-300. https://doi.org/10.1016/j.orcp.2020.07.002.

44. Pranata R, Lim MA, Yonas E, Vania R, Lukito AA, Siswanto BB, et al. Body mass index and outcome in patients with COVID-19: a dose-response meta-analysis. Diabetes Metab. 2020. https://doi. org/10.1016/j.diabet.2020.07.005.

45. Seidu S, Gillies C, Zaccardi F, Kunutsor SK, Hartmann-Boyce J, Yates T, et al. The impact of obesity on severe disease and mortality in people with SARS-CoV-2: a systematic review and metaanalysis. Endocrinol Diabetes Metab. 2020:e00176. https://doi. org/10.1002/edm2.176.

46. Huang Y, Lu Y, Huang YM, Wang M, Ling W, Sui Y, et al. Obesity in patients with COVID-19: a systematic review and meta-analysis. Metabolism. 2020;113:154378. https://doi.org/10. 1016/j.metabol.2020.154378.

47. Földi M, Farkas N, Kiss S, Dembrovszky F, Szakács Z, Balaskó $\mathrm{M}$, et al. Visceral adiposity elevates the risk of critical condition in COVID-19: a systematic review and meta-analysis. Obesity (Silver Spring). 2020. https://doi.org/10.1002/oby.23096.

48. Ho FK, Celis-Morales CA, Gray SR, Katikireddi SV, Niedzwiedz $\mathrm{CL}$, Hastie C, et al. Modifiable and non-modifiable risk factors for COVID-19, and comparison to risk factors for influenza and pneumonia: results from a UK Biobank prospective cohort study. J BMJ Open. 2020;10:e040402. https://doi.org/10.1136/bmjopen2020-040402.

49. Huizinga GP, Singer BH, Singer K. The collision of metainflammation and SARS-CoV-2 pandemic infection. 
Endocrinology. 2020;161. https://doi.org/10.1210/endocr/ bqaa154.

50. Zachariah P, Johnson CL, Halabi KC, Ahn D, Sen AI, Fischer A, et al. Epidemiology, clinical features, and disease severity in patients with coronavirus disease 2019 (COVID-19) in a children's hospital in New York City, New York. JAMA Pediatr. 2020;174: e202430. https://doi.org/10.1001/jamapediatrics.2020.2430.

51. Aung N, Khanji MY, Munroe PB, Petersen SE. Causal inference for genetic obesity, cardiometabolic profile and COVID-19 susceptibility: a Mendelian randomization study. Front Genet. 2020;11:586308. https://doi.org/10.3389/fgene.2020.586308.

52. Zheng KI, Gao F, Wang XB, Sun QF, Pan KH, Wang TY, et al. Letter to the editor: obesity as a risk factor for greater severity of COVID-19 in patients with metabolic associated fatty liver disease. Metabolism. 2020;108:154244. https://doi.org/10.1016/j. metabol.2020.154244.

53. Bansal R, Gubbi S, Muniyappa R. Metabolic syndrome and COVID 19: endocrine-immune-vascular interactions shapes clinical course. Endocrinology. 2020;161. https://doi.org/10.1210/ endocr/bqaal 12.

54. Askarpour M, Khani D, Sheikhi A, Ghaedi E, Alizadeh S. Effect of bariatric surgery on serum inflammatory factors of obese patients: a systematic review and meta-analysis. Obes Surg. 2019;29:2631-47. https://doi.org/10.1007/s11695-019-03926-0.

55. McNeill JN, Lau ES, Paniagua SM, Liu EE, Wang JK, Bassett IV, et al. The role of obesity in inflammatory markers in COVID-19 patients. Obes Res Clin Pract. 2021;15:96-9. https://doi.org/10. 1016/j.orcp.2020.12.004.

56. Nimptsch K, Konigorski S, Pischon T. Diagnosis of obesity and use of obesity biomarkers in science and clinical medicine. Metabolism. 2019;92:61-70. https://doi.org/10.1016/j.metabol. 2018.12.006.

57. Christensen RAG, Sturrock SL, Arneja J, Brooks JD. Measures of adiposity and risk of testing positive for SARS-CoV-2 in the UK Biobank study. J Obes. 2021;2021:8837319. https://doi.org/10. 1155/2021/8837319.

58. Pelosi P, Gregoretti C. Perioperative management of obese patients. Best Pract Res Clin Anaesthesiol. 2010;24:211-25. https://doi.org/10.1016/j.bpa.2010.02.001

59. Watanabe M, Caruso D, Tuccinardi D, Risi R, Zerunian M, Polici $\mathrm{M}$, et al. Visceral fat shows the strongest association with the need of intensive care in patients with COVID-19. Metabolism. 2020;111:154319. https://doi.org/10.1016/j.metabol.2020. 154319.

60. Petersen A, Bressem K, Albrecht J, Thieß HM, Vahldiek J, Hamm $\mathrm{B}$, et al. The role of visceral adiposity in the severity of COVID19: highlights from a unicenter cross-sectional pilot study in Germany. Metabolism. 2020;110:154317. https://doi.org/10. 1016/j.metabol.2020.154317.

61. Lockhart SM, O'Rahilly S. When Two pandemics meet: why is obesity associated with increased COVID-19 mortality? Med (N Y) 2020. https://doi.org/10.1016/j.medj.2020.06.005

62. Yan J, Grantham M, Pantelic J, Bueno de Mesquita PJ, Albert B, Liu F, et al. Infectious virus in exhaled breath of symptomatic seasonal influenza cases from a college community. Proc Natl Acad Sci U S A. 2018;115:1081-6. https://doi.org/10.1073/pnas. 1716561115.

63. Sales-Peres SHC, de Azevedo-Silva LJ, Bonato RCS, Sales-Peres MC, Pinto A, Santiago Junior JF. Coronavirus (SARS-CoV-2) and the risk of obesity for critically illness and ICU admitted: meta-analysis of the epidemiological evidence. Obes Res Clin Pract. 2020;14:389-97. https://doi.org/10.1016/j.orcp.2020.07. 007.

64. Smith M, Honce R, Schultz-Cherry S. Metabolic syndrome and viral pathogenesis: lessons from influenza and coronaviruses. J Virol. 2020;94. https://doi.org/10.1128/jvi.00665-20.
65. Luzi L, Radaelli MG. Influenza and obesity: its odd relationship and the lessons for COVID-19 pandemic. Acta Diabetol. 2020;57: 759-64. https://doi.org/10.1007/s00592-020-01522-8.

66. Short KR, Kedzierska K, van de Sandt CE. Back to the future: lessons learned from the 1918 influenza pandemic. Front Cell Infect Microbiol. 2018;8:343. https://doi.org/10.3389/fcimb. 2018.00343.

67. Yang L, Chan KP, Lee RS, Chan WM, Lai HK, Thach TQ, et al. Obesity and influenza associated mortality: evidence from an elderly cohort in Hong Kong. Prev Med. 2013;56:118-23. https:// doi.org/10.1016/j.ypmed.2012.11.017.

68. Moser JS, Galindo-Fraga A, Ortiz-Hernández AA, Gu W, Hunsberger S, Galán-Herrera JF, et al. Underweight, overweight, and obesity as independent risk factors for hospitalization in adults and children from influenza and other respiratory viruses. Influenza Other Respir Viruses. 2019;13:3-9. https://doi.org/10. 1111/irv.12618.

69. Neidich SD, Green WD, Rebeles J, Karlsson EA, Schultz-Cherry $\mathrm{S}$, Noah TL, et al. Increased risk of influenza among vaccinated adults who are obese. Int J Obes. 2017;41:1324-30. https://doi. org/10.1038/ijo.2017.131.

70. Honce R, Schultz-Cherry S. Impact of obesity on influenza A virus pathogenesis, immune response, and evolution. Front Immunol. 2019;10:1071. https://doi.org/10.3389/fimmu.2019. 01071.

71. Louie JK, Acosta M, Samuel MC, Schechter R, Vugia DJ, Harriman K, et al. A novel risk factor for a novel virus: obesity and 2009 pandemic influenza A (H1N1). Clin Infect Dis. 2011;52:301-12. https://doi.org/10.1093/cid/ciq152.

72. Webb SA, Pettilä V, Seppelt I, Bellomo R, Bailey M, Cooper DJ, et al. Critical care services and 2009 H1N1 influenza in Australia and New Zealand. N Engl J Med. 2009;361:1925-34. https://doi. org/10.1056/NEJMoa0908481.

73. Van Kerkhove MD, Vandemaele KA, Shinde V, JaramilloGutierrez G, Koukounari A, Donnelly CA, et al. Risk factors for severe outcomes following 2009 influenza A (H1N1) infection: a global pooled analysis. PLoS Med. 2011;8:e1001053. https://doi. org/10.1371/journal.pmed.1001053.

74. Segaloff HE, Evans R, Arshad S, Zervos MJ, Archer C, Kaye KS, et al. The impact of obesity and timely antiviral administration on severe influenza outcomes among hospitalized adults. J Med Virol. 2018;90:212-8. https://doi.org/10.1002/jmv.24946.

75. Fezeu L, Julia C, Henegar A, Bitu J, Hu FB, Grobbee DE, et al. Obesity is associated with higher risk of intensive care unit admission and death in influenza A (H1N1) patients: a systematic review and meta-analysis. Obes Rev. 2011;12:653-9. https://doi. org/10.1111/j.1467-789X.2011.00864.x.

76. Trivedi V, Bavishi C, Jean R. Impact of obesity on sepsis mortality: a systematic review. J Crit Care. 2015;30:518-24. https://doi. org/10.1016/j.jcrc.2014.12.007.

77. Braun ES, Crawford FW, Desai MM, Meek J, Kirley PD, Miller L, et al. Obesity not associated with severity among hospitalized adults with seasonal influenza virus infection. Infection. 2015;43: 569-75. https://doi.org/10.1007/s15010-015-0802-x.

78. Booth CM, Matukas LM, Tomlinson GA, Rachlis AR, Rose DB, Dwosh HA, et al. Clinical features and short-term outcomes of 144 patients with SARS in the greater Toronto area. Jama. 2003;289: 2801-9. https://doi.org/10.1001/jama.289.21.JOC30885 This important study analyzes the clinical characteristics and short-term outcomes of SARS in the first large group of patients in North America.

79. Badawi A, Ryoo SG. Prevalence of comorbidities in the Middle East respiratory syndrome coronavirus (MERS-CoV): a systematic review and meta-analysis. Int J Infect Dis. 2016;49:129-33. https://doi.org/10.1016/j.ijid.2016.06.015. 
80. Noorwali AA, Turkistani AM, Asiri SI, Trabulsi FA, Alwafi OM, Alzahrani SH, et al. Descriptive epidemiology and characteristics of confirmed cases of Middle East respiratory syndrome coronavirus infection in the Makkah Region of Saudi Arabia, March to June 2014. Ann Saudi Med. 2015;35:203-9. https://doi.org/10. 5144/0256-4947.2015.203.

81. Chan-Yeung M, Xu RH. SARS: epidemiology. Respirology. 2003;8(Suppl):S9-14. https://doi.org/10.1046/j.1440-1843.2003. 00518.x.

82. Zhao Y, Li Z, Yang T, Wang M, Xi X. Is body mass index associated with outcomes of mechanically ventilated adult patients in intensive critical units? A systematic review and meta-analysis. PLoS One. 2018;13:e0198669. https://doi.org/10.1371/journal. pone.0198669.

83. Ni YN, Luo J, Yu H, Wang YW, Hu YH, Liu D, et al. Can body mass index predict clinical outcomes for patients with acute lung injury/acute respiratory distress syndrome? A meta-analysis. Crit Care. 2017;21:36. https://doi.org/10.1186/s13054-017-1615-3 This meta-analysis has shown that obesity and severe obesity are associated with lower mortality in patients with ARDS

84. Wang S, Liu X, Chen Q, Liu C, Huang C, Fang X. The role of increased body mass index in outcomes of sepsis: a systematic review and meta-analysis. BMC Anesthesiol. 2017;17:118. https://doi.org/10.1186/s12871-017-0405-4.

85. Oliveros H, Villamor E. Obesity and mortality in critically ill adults: a systematic review and meta-analysis. Obesity (Silver Spring). 2008;16:515-21. https://doi.org/10.1038/oby.2007.102.

86. Ross PA, Klein MJ, Nguyen T, Leung D, Khemani RG, Newth CJL, et al. Body habitus and risk of mortality in pediatric sepsis and septic shock: a retrospective cohort study. J Pediatr. 2019;210: 178-83.e2. https://doi.org/10.1016/j.jpeds.2019.03.027.

87. Peterson LS, Gállego Suárez C, Segaloff HE, Griffin C, Martin ET, Odetola FO, et al. Outcomes and resource use among overweight and obese children with sepsis in the pediatric intensive care unit. J Intensive Care Med. 2020;35:472-7. https://doi.org/ 10.1177/0885066618760541.

88. Kruglikov IL, Scherer PE. The role of adipocytes and adipocytelike cells in the severity of COVID-19 infections. Obesity (Silver Spring). 2020;28:1187-90. https://doi.org/10.1002/oby.22856.

89. Ryan PM, Caplice NM. Is adipose tissue a reservoir for viral spread, immune activation, and cytokine amplification in coronavirus disease 2019? Obesity (Silver Spring). 2020;28:1191-4. https://doi.org/10.1002/oby.22843.

90. Argyropoulos KV, Serrano A, Hu J, Black M, Feng X, Shen G, et al. Association of initial viral load in severe acute respiratory syndrome coronavirus 2 (SARS-CoV-2) patients with outcome and symptoms. Am J Pathol. 2020;190:1881-7. https://doi.org/ 10.1016/j.ajpath.2020.07.001.

91. Jose RJ, Manuel A. Does coronavirus disease 2019 disprove the obesity paradox in acute respiratory distress syndrome? Obesity (Silver Spring). 2020;28:1007. https://doi.org/10.1002/oby. 22835.

92. Zhang JJ, Dong X, Cao YY, Yuan YD, Yang YB, Yan YQ, et al. Clinical characteristics of 140 patients infected with SARS-CoV-2 in Wuhan. China Allergy. 2020;75:1730-41. https://doi.org/10. 1111/all.14238

93. Mehta P, McAuley DF, Brown M, Sanchez E, Tattersall RS, Manson JJ. COVID-19: consider cytokine storm syndromes and immunosuppression. Lancet. 2020;395:1033-4. https://doi.org/ 10.1016/s0140-6736(20)30628-0.

94. Kritis P, Karampela I, Kokoris S, Dalamaga M. The combination of bromelain and curcumin as an immune-boosting nutraceutical in the prevention of severe COVID-19. Metabol Open. 2020;8: 100066. https://doi.org/10.1016/j.metop.2020.100066.
95. Karampelas M, Dalamaga M, Karampela I. Does COVID-19 involve the retina? Ophthalmol Therapy. 2020;9:693-5. https://doi. org/10.1007/s40123-020-00299-x.

96. Karampela I, Dalamaga M. Could respiratory fluoroquinolones, levofloxacin and moxifloxacin, prove to be beneficial as an adjunct treatment in COVID-19? Arch Med Res. 2020;51:741-2. https://doi.org/10.1016/j.arcmed.2020.06.004.

97. Dalamaga M, Karampela I, Mantzoros CS. Commentary: phosphodiesterase 4 inhibitors as potential adjunct treatment targeting the cytokine storm in COVID-19. Metabolism. 2020;109:154282. https://doi.org/10.1016/j.metabol.2020.154282.

98. Dalamaga M, Karampela I, Mantzoros CS. Commentary: could iron chelators prove to be useful as an adjunct to COVID-19 treatment regimens? Metabolism. 2020;108:154260. https://doi.org/ 10.1016/j.metabol.2020.154260.

99. O'Shea D, Hogan AE. Dysregulation of natural killer cells in obesity. Cancers (Basel). 2019;11. https://doi.org/10.3390/ cancers1 1040573

100. Smith AG, Sheridan PA, Harp JB, Beck MA. Diet-induced obese mice have increased mortality and altered immune responses when infected with influenza virus. J Nutr. 2007;137:1236-43. https://doi.org/10.1093/jn/137.5.1236.

101. McLaughlin T, Ackerman SE, Shen L, Engleman E. Role of innate and adaptive immunity in obesity-associated metabolic disease. J Clin Invest. 2017;127:5-13. https://doi.org/10.1172/ jci88876.

102. Giamarellos-Bourboulis EJ, Netea MG, Rovina N, Akinosoglou $\mathrm{K}$, Antoniadou A, Antonakos N, et al. Complex immune dysregulation in COVID-19 patients with severe respiratory failure. Cell Host Microbe. 2020;27:992-1000.e3. https://doi.org/10.1016/j. chom.2020.04.009.

103. Hu ZJ, Xu J, Yin JM, Li L, Hou W, Zhang LL, et al. Lower circulating interferon-gamma is a risk factor for lung fibrosis in COVID-19 patients. Front Immunol. 2020;11:585647. https://doi. org/10.3389/fimmu.2020.585647.

104. Tsigalou C, Vallianou N, Dalamaga M. Autoantibody production in obesity: is there evidence for a link between obesity and autoimmunity? Curr Obes Rep. 2020;9:245-54. https://doi.org/10. 1007/s13679-020-00397-8.

105. Paroutoglou K, Papadavid E, Christodoulatos GS, Dalamaga M. Deciphering the association between psoriasis and obesity: current evidence and treatment considerations. Curr Obes Rep. 2020;9: 165-78. https://doi.org/10.1007/s13679-020-00380-3.

106. Koliaki C, Liatis S, Dalamaga M, Kokkinos A. Sarcopenic obesity: epidemiologic evidence, pathophysiology, and therapeutic perspectives. Curr Obes Rep. 2019;8:458-71. https://doi.org/10. 1007/s13679-019-00359-9.

107. Korakas E, Ikonomidis I, Kousathana F, Balampanis K, Kountouri A, Raptis A, et al. Obesity and COVID-19: immune and metabolic derangement as a possible link to adverse clinical outcomes. Am J Physiol Endocrinol Metab. 2020;319:E105-e9. https://doi.org/10. 1152/ajpendo.00198.2020.

108. Fajgenbaum DC, June CH. Cytokine storm. N Engl J Med. 2020;383:2255-73. https://doi.org/10.1056/NEJMra2026131.

109.• Klok FA, Kruip M, van der Meer NJM, Arbous MS, Gommers D, Kant KM, et al. Confirmation of the high cumulative incidence of thrombotic complications in critically ill ICU patients with COVID-19: an updated analysis. Thromb Res. 2020;191:148 50. https://doi.org/10.1016/j.thromres.2020.04.041 In this updated analysis, it was confirmed the very high cumulative incidence of thrombotic complications in critically ill patients with COVID-19 pneumonia.

110. Lucas C, Wong P, Klein J, Castro TBR, Silva J, Sundaram M, et al. Longitudinal analyses reveal immunological misfiring in severe COVID-19. Nature. 2020;584:463-9. https://doi.org/10. 1038/s41586-020-2588-y. 
111.• Horby P, Lim WS, Emberson JR, Mafham M, Bell JL, Linsell L, et al. Dexamethasone in hospitalized patients with COVID-19 preliminary report. N Engl J Med. 2020. https://doi.org/10.1056/ NEJMoa2021436 In patients hospitalized with Covid-19, the use of dexamethasone resulted in lower 28-day mortality among those who were receiving either invasive mechanical ventilation or oxygen alone at randomization but not among those receiving no respiratory support.

112. Huang C, Wang Y, Li X, Ren L, Zhao J, Hu Y, et al. Clinical features of patients infected with 2019 novel coronavirus in Wuhan. China Lancet. 2020;395:497-506. https://doi.org/10. 1016/s0140-6736(20)30183-5.

113. Rheinheimer J, de Souza BM, Cardoso NS, Bauer AC, Crispim D. Current role of the NLRP3 inflammasome on obesity and insulin resistance: a systematic review. Metabolism. 2017;74:1-9. https:// doi.org/10.1016/j.metabol.2017.06.002.

114. Boregowda U, Perisetti A, Nanjappa A, Gajendran M, Kutti Sridharan G, Goyal H. Addition of tocilizumab to the standard of care reduces mortality in severe COVID-19: a systematic review and meta-analysis. Front Med (Lausanne). 2020;7:586221. https://doi.org/10.3389/fmed.2020.586221.

115. Putman M, Chock YPE, Tam H, Kim AHJ, Sattui SE, Berenbaum $\mathrm{F}$, et al. Antirheumatic disease therapies for the treatment of COVID-19: a systematic review and meta-analysis. Arthritis Rheum. 2020. https://doi.org/10.1002/art.41469.

116. Deftereos SG, Giannopoulos G, Vrachatis DA, Siasos GD, Giotaki SG, Gargalianos P, et al. Effect of colchicine vs standard care on cardiac and inflammatory biomarkers and clinical outcomes in patients hospitalized with coronavirus disease 2019: the GRECCO-19 randomized clinical trial. JAMA Netw Open. 2020;3:e2013136. https://doi.org/10.1001/jamanetworkopen. 2020.13136 .

117. Ribeiro SA, Lopes C, Amaral R, Amaral A. The therapeutic potential of colchicine in the complications of COVID19. Could the immunometabolic properties of an old and cheap drug help? Metabol Open. 2020;7:100045. https://doi.org/10.1016/j.metop. 2020.100045 .

118. Hermine O, Mariette X, Tharaux PL, Resche-Rigon M, Porcher R, Ravaud P. Effect of tocilizumab vs usual care in adults hospitalized with COVID-19 and moderate or severe pneumonia: a randomized clinical trial. JAMA Intern Med. 2020. https://doi.org/10. 1001/jamainternmed.2020.6820.

119. Stone JH, Frigault MJ, Serling-Boyd NJ, Fernandes AD, Harvey L, Foulkes AS, et al. Efficacy of tocilizumab in patients hospitalized with COVID-19. N Engl J Med. 2020;383:2333-44. https:// doi.org/10.1056/NEJMoa2028836.

120. Moon HS, Dalamaga M, Kim SY, Polyzos SA, Hamnvik OP, Magkos F, et al. Leptin's role in lipodystrophic and nonlipodystrophic insulin-resistant and diabetic individuals. Endocr Rev. 2013;34:377-412. https://doi.org/10.1210/er.20121053.

121. Dalamaga M, Chou SH, Shields K, Papageorgiou P, Polyzos SA, Mantzoros CS. Leptin at the intersection of neuroendocrinology and metabolism: current evidence and therapeutic perspectives. Cell Metab. 2013;18:29-42. https://doi.org/10.1016/j.cmet.2013. 05.010 .

122. Zhang AJ, To KK, Li C, Lau CC, Poon VK, Chan CC, et al. Leptin mediates the pathogenesis of severe 2009 pandemic influenza $\mathrm{A}(\mathrm{H} 1 \mathrm{~N} 1)$ infection associated with cytokine dysregulation in mice with diet-induced obesity. J Infect Dis. 2013;207:1270-80. https://doi.org/10.1093/infdis/jit031.

123. van der Voort PHJ, Moser J, Zandstra DF, Muller Kobold AC, Knoester M, Calkhoven CF, et al. Leptin levels in SARS-CoV-2 infection related respiratory failure: a cross-sectional study and a pathophysiological framework on the role of fat tissue. Heliyon. 2020;6:e4696. https://doi.org/10.1016/j.heliyon.2020.e04696.
124. Summer R, Fiack CA, Ikeda Y, Sato K, Dwyer D, Ouchi N, et al. Adiponectin deficiency: a model of pulmonary hypertension associated with pulmonary vascular disease. Am J Phys Lung Cell Mol Phys. 2009;297:L432-8. https://doi.org/10.1152/ajplung.90599. 2008.

125. Spyrou N, Avgerinos KI, Mantzoros CS, Dalamaga M. Classic and novel adipocytokines at the intersection of obesity and cancer: diagnostic and therapeutic strategies. Curr Obes Rep. 2018;7:260 75. https://doi.org/10.1007/s13679-018-0318-7.

126. Dalamaga M. Resistin as a biomarker linking obesity and inflammation to cancer: potential clinical perspectives. Biomark Med. 2014;8:107-18. https://doi.org/10.2217/bmm.13.99.

127. Meizlish ML, Pine AB, Bishai JD, Goshua G, Nadelmann ER, Simonov M, et al. A neutrophil activation signature predicts critical illness and mortality in COVID-19. medRxiv. 2020. https:// doi.org/10.1101/2020.09.01.20183897.

128. Karampela I, Christodoulatos GS, Kandri E, Antonakos G, Vogiatzakis E, Dimopoulos G, et al. Circulating eNampt and resistin as a proinflammatory duet predicting independently mortality in critically ill patients with sepsis: a prospective observational study. Cytokine. 2019;119:62-70. https://doi.org/10.1016/ j.cyto.2019.03.002.

129. Ackermann M, Verleden SE, Kuehnel M, Haverich A, Welte T, Laenger F, et al. Pulmonary vascular endothelialitis, thrombosis, and angiogenesis in COVID-19. N Engl J Med. 2020;383:120-8. https://doi.org/10.1056/NEJMoa2015432.

130. Varga Z, Flammer AJ, Steiger P, Haberecker M, Andermatt R, Zinkernagel AS, et al. Endothelial cell infection and endotheliitis in COVID-19. Lancet. 2020;395:1417-8. https://doi.org/10.1016/ s0140-6736(20)30937-5.

131. Hamming I, Timens W, Bulthuis ML, Lely AT, Navis G, van Goor H. Tissue distribution of ACE2 protein, the functional receptor for SARS coronavirus. A first step in understanding SARS pathogenesis. J Pathol. 2004;203:631-7. https://doi.org/10.1002/ path. 1570 .

132. van der Heijden DJ, van Leeuwen MAH, Janssens GN, Lenzen MJ, van de Ven PM, Eringa EC, et al. Body mass index is associated with microvascular endothelial dysfunction in patients with treated metabolic risk factors and suspected coronary artery disease. J Am Heart Assoc. 2017;6. https://doi.org/10.1161/jaha.117. 006082.

133. Moral-Sanz J, Menendez C, Moreno L, Moreno E, Cogolludo A, Perez-Vizcaino F. Pulmonary arterial dysfunction in insulin resistant obese Zucker rats. Respir Res. 2011;12:51. https://doi.org/10. 1186/1465-9921-12-51.

134. Aroor AR, Jia G, Sowers JR. Cellular mechanisms underlying obesity-induced arterial stiffness. Am J Phys Regul Integr Comp Phys. 2018;314:R387-r98. https://doi.org/10.1152/ajpregu. 00235.2016.

135. Ray S, Miglio C, Eden T, Del Rio D. Assessment of vascular and endothelial dysfunction in nutritional studies. Nutr Metab Cardiovasc Dis. 2014;24:940-6. https://doi.org/10.1016/j. numecd.2014.03.011.

136. Piazza G, Campia U, Hurwitz S, Snyder JE, Rizzo SM, Pfeferman $\mathrm{MB}$, et al. Registry of arterial and venous thromboembolic complications in patients with COVID-19. J Am Coll Cardiol. 2020;76:2060-72. https://doi.org/10.1016/j.jacc.2020.08.070 In this study, it was shown that major arterial or venous thromboembolism, major adverse cardiovascular events, and symptomatic venous thromboembolism occurred with high frequency in patients with COVID-19, especially in the intensive care setting, despite a high utilization rate of thromboprophylaxis.

137. Ozsu S, Gunay E, Konstantinides SV. A review of venous thromboembolism in COVID-19: a clinical perspective. Clin Respir J. 2021. https://doi.org/10.1111/crj.13330. 
138. Nicolai L, Leunig A, Brambs S, Kaiser R, Weinberger T, Weigand $\mathrm{M}$, et al. Immunothrombotic dysregulation in COVID-19 pneumonia is associated with respiratory failure and coagulopathy. Circulation. 2020;142:1176-89. https://doi.org/10.1161/ circulationaha. 120.048488 .

139. Magro C, Mulvey JJ, Berlin D, Nuovo G, Salvatore S, Harp J, et al. Complement associated microvascular injury and thrombosis in the pathogenesis of severe COVID-19 infection: a report of five cases. Transl Res. 2020;220:1-13. https://doi.org/10.1016/j.trsl. 2020.04.007.

140. Piazza G, Morrow DA. Diagnosis, management, and pathophysiology of arterial and venous thrombosis in COVID-19. Jama. 2020. https://doi.org/10.1001/jama.2020.23422.

141. Blokhin IO, Lentz SR. Mechanisms of thrombosis in obesity. Curr Opin Hematol. 2013;20:437-44. https://doi.org/10.1097/MOH. 0b013e3283634443.

142. Xin Y, Hertle E, van der Kallen CJH, Schalkwijk CG, Stehouwer CDA, van Greevenbroek MMJ. Longitudinal associations of the alternative and terminal pathways of complement activation with adiposity: the CODAM study. Obes Res Clin Pract. 2018;12:28692. https://doi.org/10.1016/j.orcp.2017.11.002.

143. Vlaicu SI, Tatomir A, Boodhoo D, Vesa S, Mircea PA, Rus H. The role of complement system in adipose tissue-related inflammation. Immunol Res. 2016;64:653-64. https://doi.org/10.1007/ s12026-015-8783-5.

144. Wong C, Marwick TH. Obesity cardiomyopathy: pathogenesis and pathophysiology. Nat Clin Pract Cardiovasc Med. 2007;4: 436-43. https://doi.org/10.1038/ncpcardio0943.

145. Alpert MA, Lavie CJ, Agrawal H, Aggarwal KB, Kumar SA. Obesity and heart failure: epidemiology, pathophysiology, clinical manifestations, and management. Transl Res. 2014;164:345-56. https://doi.org/10.1016/j.trsl.2014.04.010.

146. Kuba K, Imai Y, Rao S, Gao H, Guo F, Guan B, et al. A crucial role of angiotensin converting enzyme 2 (ACE2) in SARS coronavirus-induced lung injury. Nat Med. 2005;11:875-9. https://doi.org/10.1038/nm1267.

147. López-Cano C, Lecube A, García-Ramírez M, Muñoz X, Sánchez E, Seminario A, et al. Serum surfactant protein $d$ as a biomarker for measuring lung involvement in obese patients with type 2 diabetes. J Clin Endocrinol Metab. 2017;102:4109-16. https:// doi.org/10.1210/jc.2017-00913.

148. Foster DJ, Ravikumar P, Bellotto DJ, Unger RH, Hsia CC. Fatty diabetic lung: altered alveolar structure and surfactant protein expression. Am J Phys Lung Cell Mol Phys. 2010;298:L392-403. https://doi.org/10.1152/ajplung.00041.2009.

149. Dai YB, Miao YF, Wu WF, Li Y, D'Errico F, Su W, et al. Ablation of liver $\mathrm{X}$ receptors $\alpha$ and $\beta$ leads to spontaneous peripheral squamous cell lung cancer in mice. Proc Natl Acad Sci U S A. 2016;113:7614-9. https://doi.org/10.1073/pnas.1607590113.

150. Maier HE, Lopez R, Sanchez N, Ng S, Gresh L, Ojeda S, et al. Obesity increases the duration of influenza A virus shedding in adults. J Infect Dis. 2018;218:1378-82. https://doi.org/10.1093/ infdis/jiy370.

151. Khan MMA, Khan MN, Mustagir MG, Rana J, Islam MS, Kabir MI. Effects of underlying morbidities on the occurrence of deaths in COVID-19 patients: a systematic review and meta-analysis. J Glob Health. 2020;10:020503. https://doi.org/10.7189/jogh.10. 020503 .

152. Rodgers GP, Gibbons GH. Obesity and hypertension in the time of COVID-19. Jama. 2020;324:1163-5. https://doi.org/10.1001/ jama.2020.16753.

153. Codo AC, Davanzo GG, Monteiro LB, de Souza GF, Muraro SP, Virgilio-da-Silva JV, et al. Elevated glucose levels favor SARSCoV-2 infection and monocyte response through a HIF- $1 \alpha /$ glycolysis-dependent axis. Cell Metab. 2020;32:498-9. https://doi. org/10.1016/j.cmet.2020.07.015.
154. Tsai S, Clemente-Casares X, Zhou AC, Lei H, Ahn JJ, Chan YT, et al. Insulin receptor-mediated stimulation boosts T cell immunity during inflammation and infection. Cell Metab. 2018;28:92234.e4. https://doi.org/10.1016/j.cmet.2018.08.003.

155. Zhu L, She ZG, Cheng X, Qin JJ, Zhang XJ, Cai J, et al. Association of blood glucose control and outcomes in patients with COVID-19 and pre-existing type 2 diabetes. Cell Metab. 2020;31:1068-77.e3. https://doi.org/10.1016/j.cmet.2020.04. 021.

156. Pereira M, Dantas Damascena A, Galvão Azevedo LM, de Almeida OT, da Mota Santana J. Vitamin D deficiency aggravates COVID-19: systematic review and meta-analysis. Crit Rev Food Sci Nutr. 2020:1-9. https://doi.org/10.1080/10408398.2020. 1841090.

157. Hastie CE, Mackay DF, Ho F, Celis-Morales CA, Katikireddi SV, Niedzwiedz CL, et al. Vitamin D concentrations and COVID-19 infection in UK Biobank. Diabetes Metab Syndr. 2020;14:561-5. https://doi.org/10.1016/j.dsx.2020.04.050.

158. Munshi R, Hussein MH, Toraih EA, Elshazli RM, Jardak C, Sultana N, et al. Vitamin D insufficiency as a potential culprit in critical COVID-19 patients. J Med Virol. 2020. https://doi.org/10. 1002/jmv.26360.

159. Coperchini F, Chiovato L, Croce L, Magri F, Rotondi M. The cytokine storm in COVID-19: an overview of the involvement of the chemokine/chemokine-receptor system. Cytokine Growth Factor Rev. 2020;53:25-32. https://doi.org/10.1016/j.cytogfr. 2020.05.003.

160. Dimakopoulos I, Magriplis E, Mitsopoulou AV, Karageorgou D, Bakogianni I, Micha R, et al. Association of serum vitamin D status with dietary intake and sun exposure in adults. Clin Nutr ESPEN. 2019;34:23-31. https://doi.org/10.1016/j.clnesp.2019. 09.008 .

161. Barrea L, Savastano S, Di Somma C, Savanelli MC, Nappi F, Albanese L, et al. Low serum vitamin D-status, air pollution and obesity: a dangerous liaison. Rev Endocr Metab Disord. 2017;18: 207-14. https://doi.org/10.1007/s11154-016-9388-6.

162. Dalamaga M, Muscogiuri G, Paganitsa G, Parvouleskou G, Syriou V, Karagkoynis P, et al. Adherence to the Mediterranean diet is an independent predictor of circulating vitamin D levels in normal weight and non-smoker adults: an observational crosssectional study. Int J Food Sci Nutr. 2021:1-13. https://doi.org/ 10.1080/09637486.2021.1878488.

163. Santaolalla A, Beckmann K, Kibaru J, Josephs D, Van Hemelrijck $\mathrm{M}$, Irshad S. Association between vitamin D and novel SARSCoV-2 respiratory dysfunction - a scoping review of current evidence and its implication for COVID-19 pandemic. Front Physiol. 2020;11:564387. https://doi.org/10.3389/fphys.2020.564387.

164. Confalonieri M, Salton F, Fabiano F. Acute respiratory distress syndrome. Eur Respir Rev. 2017;26. https://doi.org/10.1183/ 16000617.0116-2016.

165. Walton GE, Gibson GR, Hunter KA. Mechanisms linking the human gut microbiome to prophylactic and treatment strategies for COVID-19. Br J Nutr. 2020:1-9. https://doi.org/10.1017/ s0007114520003980.

166. Vallianou N, Stratigou T, Christodoulatos GS, Dalamaga M. Understanding the role of the gut microbiome and microbial metabolites in obesity and obesity-associated metabolic disorders: Current Evidence and Perspectives. Curr Obes Rep. 2019;8: 317-32. https://doi.org/10.1007/s13679-019-00352-2.

167. Vallianou N, Liu J, Dalamaga M. What are the key points in the association between the gut microbiome and nonalcoholic fatty liver disease? Metabol Open. 2019;1:9-10. https://doi.org/10. 1016/j.metop.2019.02.003.

168. Vallianou N, Stratigou T, Christodoulatos GS, Tsigalou C, Dalamaga M. Probiotics, prebiotics, synbiotics, postbiotics, and obesity: current evidence, controversies, and perspectives. Curr 
Obes Rep. 2020;9:179-92. https://doi.org/10.1007/s13679-02000379-w.

169. Petruk G, Puthia M, Petrlova J, Strömdahl A-C, Kjellström S, Schmidtchen A. SARS-CoV-2 Spike protein binds to bacterial lipopolysaccharide and boosts proinflammatory activity. 2020: 2020.06.29.175844. 10.1101/2020.06.29.175844 \%J bioRxiv

170. Muscogiuri G, Pugliese G, Barrea L, Savastano S, Colao A. Commentary: obesity: the "achilles heel" for COVID-19? Metabolism. 2020;108:154251. https://doi.org/10.1016/j. metabol.2020.154251.

171. Finer N, Garnett SP, Bruun JM. COVID-19 and obesity. Clin Obes. 2020;10:e12365. https://doi.org/10.1111/cob.12365.

172. Dixon AE, Peters U. The effect of obesity on lung function. Expert Rev Respir Med. 2018;12:755-67. https://doi.org/10.1080/ 17476348.2018.1506331.

173. Hamer M, Kivimäki M, Gale CR, Batty GD. Lifestyle risk factors for cardiovascular disease in relation to COVID-19 hospitalization: a community-based cohort study of 387,109 adults in UK. medRxiv. 2020;2020.05.09.20096438.10.1101/ 2020.05.09.20096438

174. Li S, Hua X. Modifiable lifestyle factors and severe COVID-19 risk: a Mendelian randomisation study. BMC Med Genet. 2021;14:38. https://doi.org/10.1186/s12920-021-00887-1.

175. Hruby A, Lieberman HR, Smith TJ. Symptoms of depression, anxiety, and post-traumatic stress disorder and their relationship to health-related behaviors in over 12,000 US military personnel: bi-directional associations. J Affect Disord. 2021;283:84-93. https://doi.org/10.1016/j.jad.2021.01.029.

176. Phelan SM, Burgess DJ, Yeazel MW, Hellerstedt WL, Griffin JM, van Ryn M. Impact of weight bias and stigma on quality of care and outcomes for patients with obesity. Obes Rev. 2015;16:31926. https://doi.org/10.1111/obr.12266.

177. Persky S, Eccleston CP. Medical student bias and care recommendations for an obese versus non-obese virtual patient. Int J Obes. 2011;35:728-35. https://doi.org/10.1038/ijo.2010.173

178. Puhl RM, Luedicke J, Grilo CM. Obesity bias in training: attitudes, beliefs, and observations among advanced trainees in professional health disciplines. Obesity (Silver Spring). 2014;22: 1008-15. https://doi.org/10.1002/oby.20637.

179. Drury CA, Louis M. Exploring the association between body weight, stigma of obesity, and health care avoidance. J Am Acad Nurse Pract. 2002;14:554-61. https://doi.org/10.1111/j. 1745-7599.2002.tb00089.x.

180. Townsend MJ, Kyle TK, Stanford FC. Commentary: COVID-19 and obesity: exploring biologic vulnerabilities, structural disparities, and weight stigma. Metabolism. 2020;110:154316. https:// doi.org/10.1016/j.metabol.2020.154316.

181. Flint SW. Stigmatizing media portrayal of obesity during the coronavirus (COVID-19) pandemic. Front Psychol. 2020;11:2124. https://doi.org/10.3389/fpsyg.2020.02124

182.• Belanger MJ, Hill MA, Angelidi AM, Dalamaga M, Sowers JR, Mantzoros CS. COVID-19 and disparities in nutrition and obesity. N Engl J Med. 2020;383:e69. https://doi.org/10.1056/ NEJMp2021264 This perspective article gives an emphasis on disparities in nutrition and obesity and COVID-19.

183. Wadhera RK, Wadhera P, Gaba P, Figueroa JF, Joynt Maddox KE, Yeh RW, et al. Variation in COVID-19 hospitalizations and deaths across New York City boroughs. Jama. 2020;323:2192-5. https://doi.org/10.1001/jama.2020.7197.

184. Di Renzo L, Gualtieri P, Pivari F, Soldati L, Attinà A, Cinelli G, et al. Eating habits and lifestyle changes during COVID-19 lockdown: an Italian survey. J Transl Med. 2020;18:229. https://doi. org/10.1186/s12967-020-02399-5.

185. Angelidi AM, Kokkinos A, Katechaki E, Ros E, Mantzoros CS. Mediterranean diet as a nutritional approach for COVID-19.
Metabolism. 2021;114:154407. https://doi.org/10.1016/j. metabol.2020.154407.

186. Di Renzo L, Gualtieri P, Pivari F, Soldati L, Attinà A, Leggeri C, et al. COVID-19: is there a role for immunonutrition in obese patient? J Transl Med. 2020;18:415. https://doi.org/10.1186/ s12967-020-02594-4.

187. Estruch R, Ros E, Salas-Salvadó J, Covas MI, Corella D, Arós F, et al. Primary prevention of cardiovascular disease with a Mediterranean diet supplemented with extra-virgin olive oil or nuts. N Engl J Med. 2018;378:e34. https://doi.org/10.1056/ NEJMoa1800389.

188. Korovesi A, Dalamaga M, Kotopouli M, Papadavid E. Adherence to the Mediterranean diet is independently associated with psoriasis risk, severity, and quality of life: a cross-sectional observational study. Int J Dermatol. 2019;58:e164-e5. https://doi.org/10.1111/ ijd.14523.

189. Aminian A, Fathalizadeh A, Tu C, Butsch WS, Pantalone KM, Griebeler ML, et al. Association of prior metabolic and bariatric surgery with severity of coronavirus disease 2019 (COVID-19) in patients with obesity. Surg Obes Relat Dis. 2020. https://doi.org/ 10.1016/j.soard.2020.10.026.

190. Iannelli A, Bouam S, Schneck AS, Frey S, Zarca K, Gugenheim J, et al. The impact of previous history of bariatric surgery on outcome of COVID-19. A nationwide medico-administrative French study. Obes Surg. 2020:1-9. https://doi.org/10.1007/s11695-02005120-z.

191. Uccelli M, Cesana GC, De Carli SM, Ciccarese F, Oldani A, Zanoni AAG, et al. COVID-19 and obesity: is bariatric surgery protective? Retrospective analysis on 2145 patients undergone bariatric-metabolic surgery from high volume center in Italy (Lombardy). Obes Surg. 2020:1-7. https://doi.org/10.1007/ s11695-020-05085-Z.

192. Ali N. Role of vitamin D in preventing of COVID-19 infection, progression and severity. J Infect Public Health. 2020;13:137380. https://doi.org/10.1016/j.jiph.2020.06.021.

193. Karampela I, Nikolopoulos M, Tzortzis E, Stratigou T, Antonakos $\mathrm{G}$, Diomidous M, et al. Remote monitoring of patients in quarantine in the era of SARS-CoV-2 pandemic. Stud Health Technol Inform. 2020;272:33-4. https://doi.org/10.3233/shti200486.

194. Wong CK, Ho DTY, Tam AR, Zhou M, Lau YM, Tang MOY, et al. Artificial intelligence mobile health platform for early detection of COVID-19 in quarantine subjects using a wearable biosensor: protocol for a randomised controlled trial. BMJ Open. 2020;10:e038555. https://doi.org/10.1136/bmjopen-2020038555.

195. Drucker DJ. Coronavirus infections and type 2 diabetes-shared pathways with therapeutic implications. Endocr Rev. 2020;41. https://doi.org/10.1210/endrev/bnaa011.

196. Lim S, Bae JH, Kwon HS, Nauck MA. COVID-19 and diabetes mellitus: from pathophysiology to clinical management. Nat Rev Endocrinol. 2021;17:11-30. https://doi.org/10.1038/s41574-02000435-4.

197. Scheen AJ. DPP-4 inhibition and COVID-19: from initial concerns to recent expectations. Diabetes Metab. 2020. https://doi. org/10.1016/j.diabet.2020.11.005.

198. Statement from the American Heart Association, the Heart Failure Society of America and the American College of Cardiology. Patients taking ACE-i and ARBs who contract COVID-19 should continue treatment, unless otherwise advised by their physician. 2020. https://newsroom.heart.org/news/patients-taking-ace-i-andarbs-who-contract-covid-19-should-continue-treatment-unlessotherwise-advised-by-their-physician. Accessed 18 Dec 2020.

199. Bornstein SR, Rubino F, Khunti K, Mingrone G, Hopkins D, Birkenfeld AL, et al. Practical recommendations for the management of diabetes in patients with COVID-19. Lancet Diabetes 
Endocrinol. 2020;8:546-50. https://doi.org/10.1016/s22138587(20)30152-2.

200. Ji D, Zhang M, Qin E, Zhang L, Xu J, Wang Y, et al. Letter to the editor: obesity, diabetes, non-alcoholic fatty liver disease and metabolic dysfunction associated fatty liver disease are proinflammatory hypercoagulable states associated with severe disease and thrombosis in COVID-19. Metabolism. 2020;115:154437. https://doi.org/10.1016/j.metabol.2020.154437.

201. Ji D, Qin E, Xu J, Zhang D, Cheng G, Wang Y, et al. Nonalcoholic fatty liver diseases in patients with COVID-19: a retrospective study. J Hepatol. 2020;73:451-3. https://doi.org/10. 1016/j.jhep.2020.03.044.

202. Shrestha DB, Budhathoki P, Syed NI, Rawal E, Raut S, Khadka S. Remdesivir: a potential game-changer or just a myth? A systematic review and meta-analysis. Life Sci. 2020;264:118663. https:// doi.org/10.1016/j.lfs.2020.118663.

203. Charan J, Kaur RJ, Bhardwaj P, Haque M, Sharma P, Misra S, et al. Rapid review of suspected adverse drug events due to remdesivir in the WHO database; findings and implications. Expert Rev Clin Pharmacol. 2020. https://doi.org/10.1080/ 17512433.2021 .1856655$.

204. FDA's approval of Veklury (remdesivir) for the treatment of COVID-19-the science of safety and effectiveness. 2020. https:// www.fda.gov/drugs/drug-safety-and-availability/fdas-approvalveklury-remdesivir-treatment-covid-19-science-safety-andeffectiveness. Accessed 18 Dec 2020.

205. Coronavirus disease 2019 (COVID-19): management in hospitalized adults. 2020. https://www.uptodate.com/contents/ coronavirus-disease-2019-covid-19-management-in-hospitalizedadults\#H3527358036. Accessed 18 Dec 2020.

206. Allegra A, Innao V, Allegra AG, Musolino C. Coagulopathy and thromboembolic events in patients with SARS-CoV-2 infection: pathogenesis and management strategies. Ann Hematol. 2020;99: 1953-65. https://doi.org/10.1007/s00277-020-04182-4.
207. A study of rivaroxaban to reduce the risk of major venous and arterial thrombotic events, hospitalization and death in medically ill outpatients with acute, symptomatic coronavirus disease 2019 (COVID-19) infection (PREVENT-HD). 2020. https:// clinicaltrials.gov/ct2/show/NCT04508023. Accessed 18 Dec 2020.

208. Coronavirus (COVID-19) update: FDA authorizes monoclonal antibody for treatment of COVID-19. 2020. https://www.fda. gov/news-events/press-announcements/coronavirus-covid-19update-fda-authorizes-monoclonal-antibody-treatment-covid-19. Accessed 18 Dec 2020.

209. Baum A, Ajithdoss D, Copin R, Zhou A, Lanza K, Negron N, et al. REGN-COV2 antibodies prevent and treat SARS-CoV-2 infection in rhesus macaques and hamsters. Science. 2020;370: 1110-5. https://doi.org/10.1126/science.abe2402.

210. Pestine E, Stokes A, Trinquart L. Representation of obese participants in obesity-related cancer randomized trials. Ann Oncol. 2018;29:1582-7. https://doi.org/10.1093/annonc/mdy138.

211. Obesity epidemic threatens effectiveness of any COVID-19 vaccine - Medscape Aug 06, 2020. https://www.medscape.com/ viewarticle/935289 Accessed 18 Dec 2020.

212. Baden LR, El Sahly HM, Essink B, Kotloff K, Frey S, Novak R, et al. Efficacy and safety of the mRNA-1273 SARS-CoV-2 vaccine. N Engl J Med. 2021;384:403-16. https://doi.org/10.1056/ NEJMoa2035389.

213. Polack FP, Thomas SJ, Kitchin N, Absalon J, Gurtman A, Lockhart S, et al. Safety and efficacy of the BNT162b2 mRNA COVID-19 vaccine. N Engl J Med. 2020;383:2603-15. https:// doi.org/10.1056/NEJMoa2034577.

Publisher's Note Springer Nature remains neutral with regard to jurisdictional claims in published maps and institutional affiliations. 